\title{
A Decisional Process Model for Stewardship
}

Environmental Assessment Division Argonne National Laboratory

Operated by The University of Chicago, under Contract W-31-109-Eng-38, for the

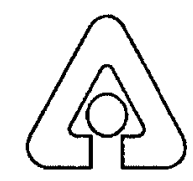

United States Department of Energy 


\section{Argonne National Laboratory}

Argonne National Laboratory, with facilities in the states of Illinois and Idaho, is owned by the United States Government and operated by The University of Chicago under the provisions of a contract with the Department of Energy.

This technical memorandum is a product of Argonne's Environmental Assessment Division (EAD). For information on the division's scientific and engineering activities, contact:

Director, Environmental Assessment Division

Argonne National Laboratory

Argonne, Illinois 60439

Telephone (630) 252-3107

Presented in this technical memorandum are preliminary results of ongoing work or work that is more limited in scope and depth than that described in formal reports issued by the EAD.

Publishing support services were provided by Argonne's Information and Publishing Division (for more information, see IPD's home page: http://www.ipd.anl.gov/).

\section{Disclaimer}

This report was prepared as an account of work sponsored by an agency of the United States Government. Neither the United States Government nor any agency thereof, nor The University of Chicago, nor any of their employees or officers, makes any warranty, express or implied, or assumes any legal liability or responsibility for the accuracy, completeness, or usefulness of any information, apparatus, product, or process disclosed, or represents that its use would not infringe privately owned rights. Reference herein to any specific commercial product, process, or service by trade name, trademark, manufacturer, or otherwise does not necessarily constitute or imply its endorsement, recommendation, or favoring by the United States Government or any agency thereof. The views and opinions of document authors expressed herein do not necessarily state or reflect those of the United States Government or any agency thereof, Argonne National Laboratory, or The University of Chicago. 


\section{A Decisional Process Model for Stewardship}

by E. Hocking, R. Johnson, L. Martino, and D. Elcock

Environmental Assessment Division

Argonne National Laboratory, 9700 South Cass Avenue, Argonne, Illinois 60439

March 2001

Work sponsored by U.S. Department of Energy. 
This report is printed on recycled paper. 
Contents

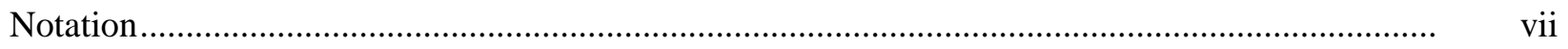

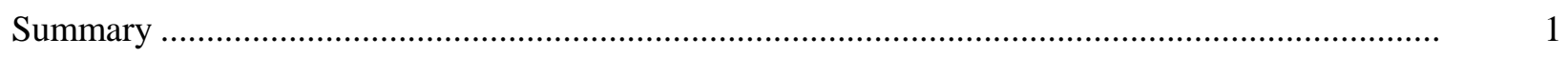

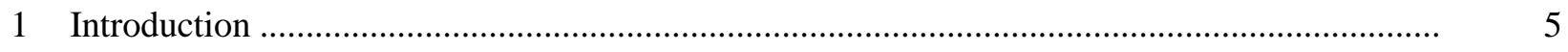

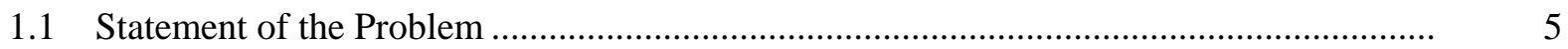

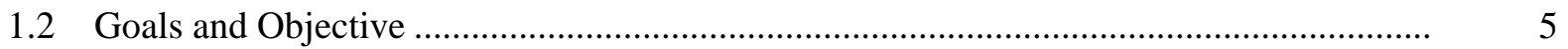

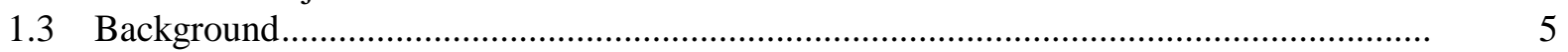

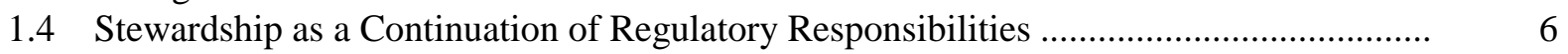

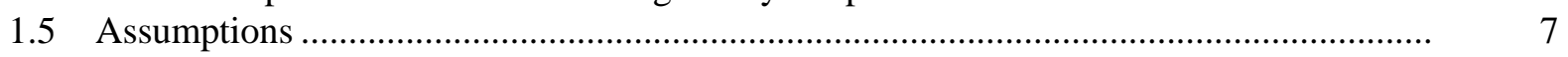

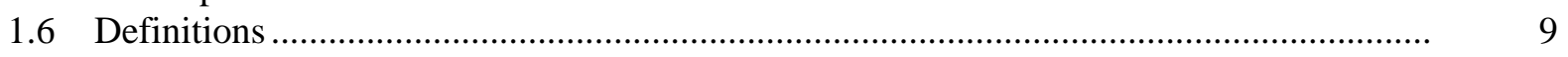

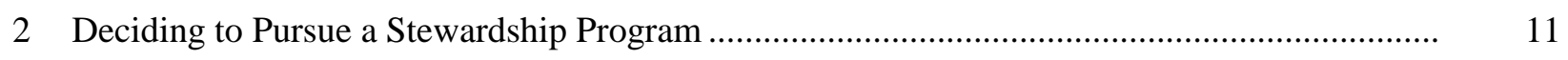

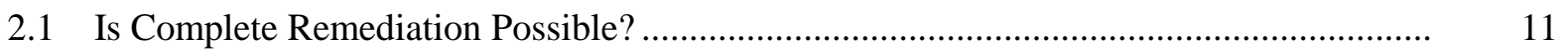

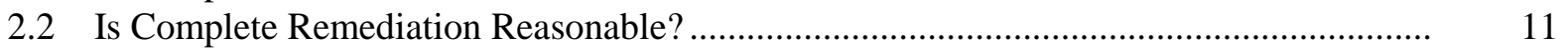

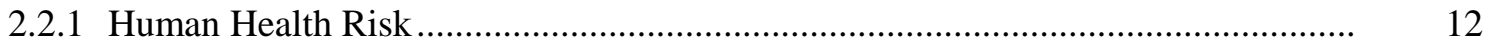

2.2.2 Collateral Damage .......................................................................................... 12

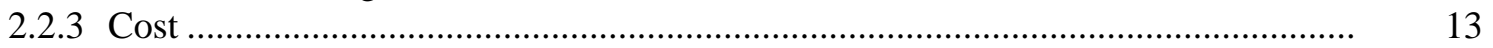

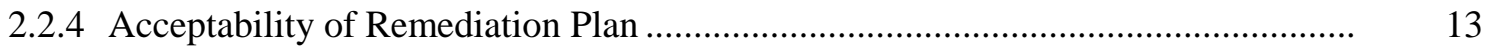

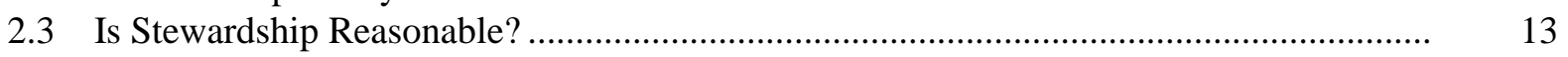

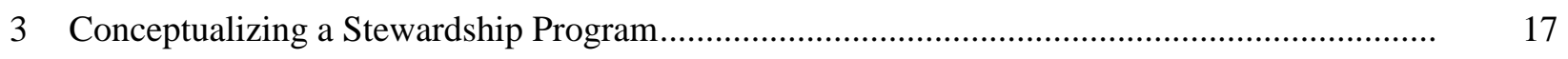

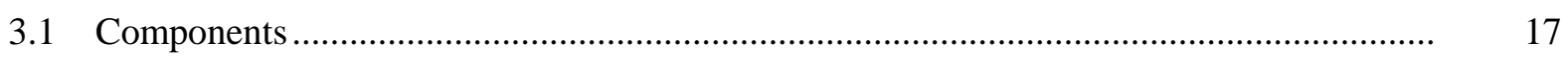

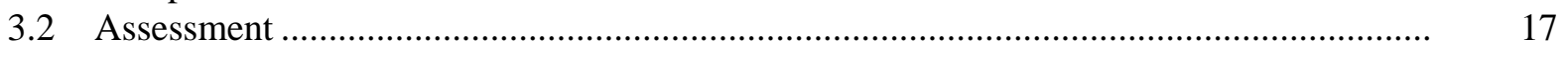

4 Evaluating a Stewardship Program as an Alternative to Complete Remediation ...................... 21

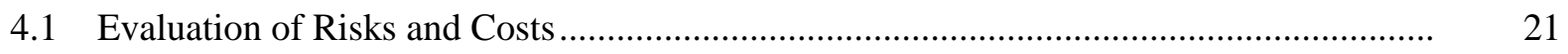

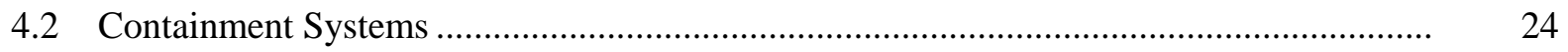

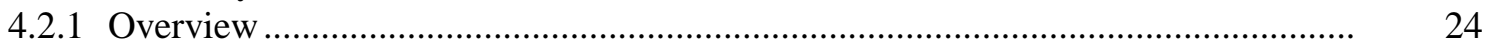

4.2.2 Attributes of Containment Systems ................................................................. 25

4.2.3 Evaluating the Risks and Costs Associated with Containment Systems ................ 25

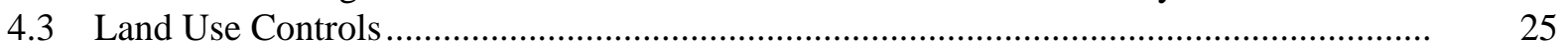

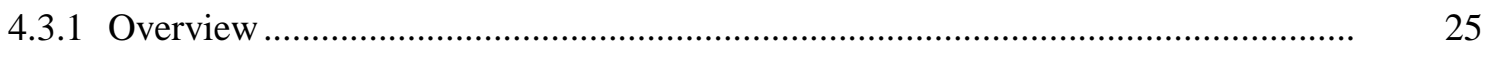

4.3.2 Attributes of Land Use Controls ….................................................................... 26

4.3.3 Evaluating the Risks and Costs Associated with Land Use Controls ..................... 27

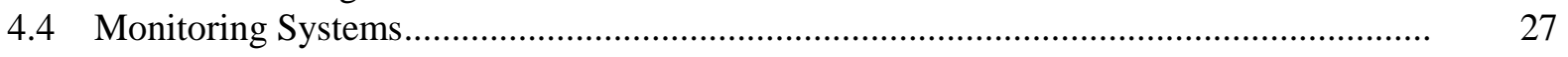

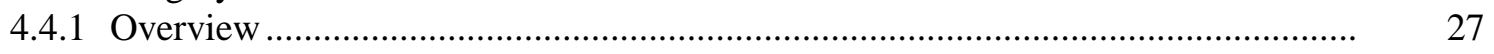

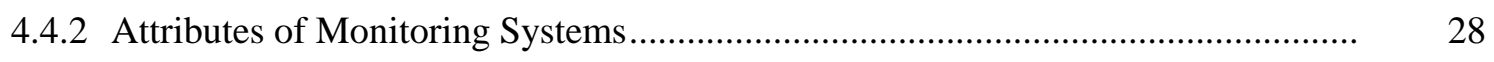


4.4.3 Evaluating the Risks and Costs Associated with Monitoring Systems................... 29

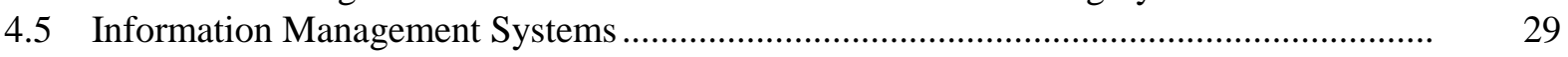

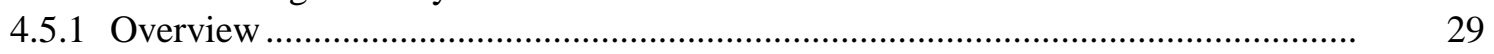

4.5.2 Attributes of Information Management Systems ................................................ 30

4.5.3 Evaluating the Risks and Costs Associated with an Information

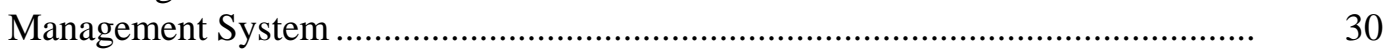

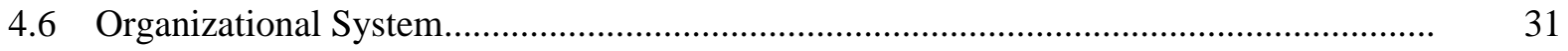

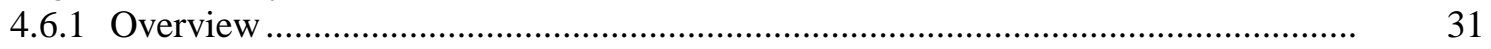

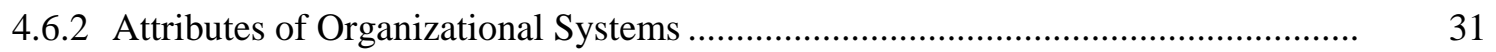

4.6.3 Evaluating the Risks and Costs of Organizational Systems.................................. 31

4.7 Designing Stewardship Programs to Facilitate Evaluation .............................................

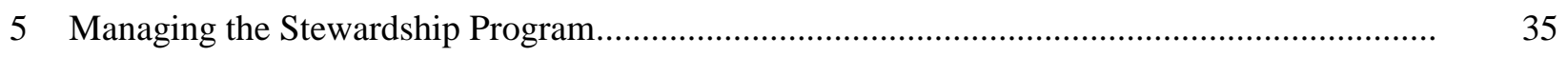

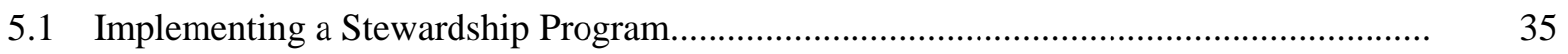

5.2 Monitoring a Stewardship Program and Managing Information..................................... 36

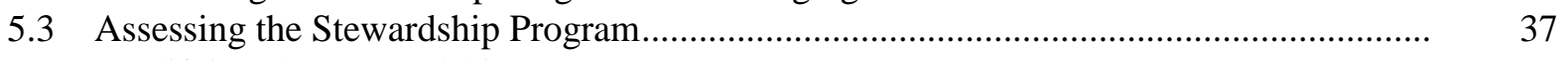

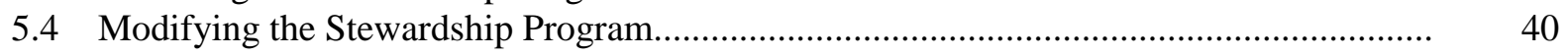

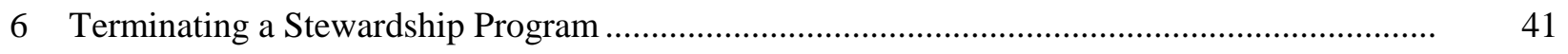

7 Scientific and Technical Developments Necessary for Stewardship Programs ........................ 43

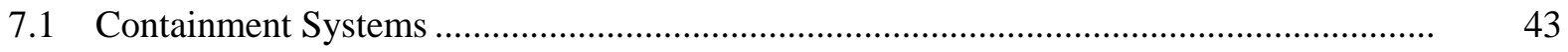

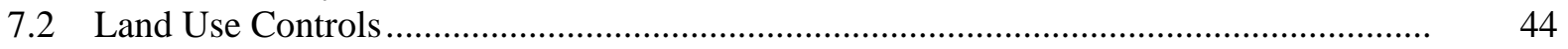

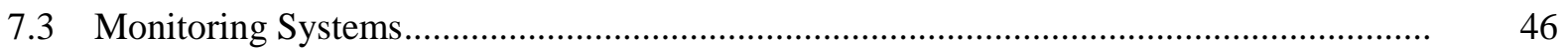

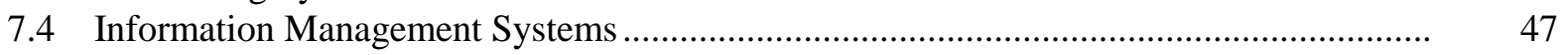

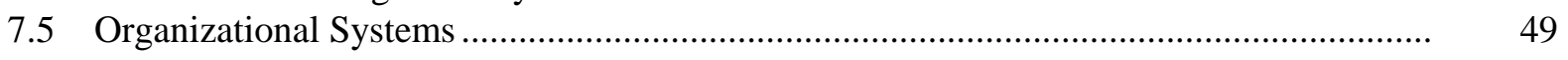

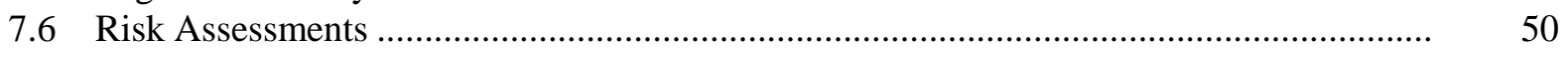

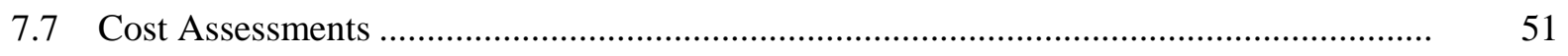

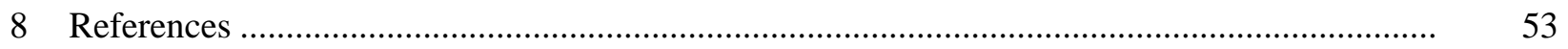

\section{Figures}

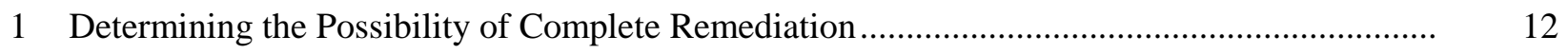

2 Determining the Reasonability of Complete Remediation .................................................. 14

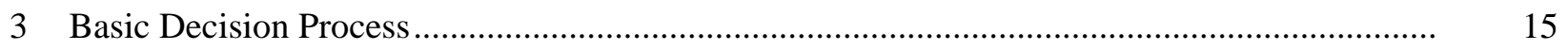

4 A Stewardship Program Is an Iterative Process ................................................................... 19

5 Site Information Needed to Evaluate Risk and Cost of a Stewardship Program........................ 22 
6 Information Needed to Evaluate the Risks and Costs Associated with Stewardship Components

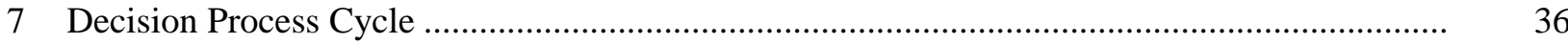

8 Assessing the Future of the Stewardship Program .............................................................. 39

\section{Table}

1 Designing and Evaluating Potential Stewardship Programs 
$\Delta$ 
The following is a list of acronyms, abbreviations, and initialisms used in this document:

CERCLA Comprehensive Environmental Response, Compensation, and Liability Act

DNAPL dense nonaqueous-phase liquids

DOD U.S. Department of Defense

DOE U.S. Department of Energy

FUSRAP Formerly Utilized Site Remedial Action Program

FY fiscal year

RCRA Resource Conservation and Recovery Act

UMTRA Uranium Mill Tailings Remedial Action

WIPP Waste Isolation Pilot Plant 



\section{Summary}

As federal and state government agencies and private sector parties pursue environmental remediation programs, some form of continuing care, or stewardship, will be required at contaminated sites that are not completely remediated. Decisions on whether a stewardship program is preferable to complete remediation are based on the risks and costs associated with each approach. If the decision is made to develop and implement a stewardship program, its risks and costs must be periodically reassessed to determine if complete remediation has become preferable in light of newly emerging remediation technologies. If it has not and stewardship will continue, the periodic risk and cost reassessment results are used to identify any need for stewardship modification, as well as opportunities to further reduce risks and costs through improved technological development. Thus, stewardship is an iterative process to achieve the lowest possible risks and costs. Because of the long time frames involved with some stewardship programs, technology development should be directed toward reliable and replaceable technologies to reduce risks and costs.

Stewardship, as it is used in this report, consists of all activities required to protect human health and the environment from hazards remaining at a site. Hazards, in the form of contaminants, would be left at a site because the site conditions could not be completely remediated. Complete remediation might not be possible at some sites because of lack of scientific understanding, adequate site characterization, or technological capability.

At other sites, complete remediation might be scientifically and technologically possible, but it might not be reasonable or acceptable to decision makers because of concerns that the side effects of complete remediation might outweigh its benefits. These side effects could include increased health and safety risks to workers and members of the public at the site as a result of the remediation activities. If wastes were sent off-site, such health and safety risks could occur at the site receiving them and along the transportation corridors between the sending and receiving sites. Other side effects of concern could be the loss of or damage to natural and cultural resources or the cost of complete remediation. The concerns expressed by decision makers can have their basis in objective, quantitative risk and cost assessments, but they can also be heavily influenced by subjective valuations. Regardless of their nature or origin, these concerns can carry enough weight to make complete remediation appear to be an unreasonable or unacceptable option.

Stewardship becomes the default scenario when it appears that sites cannot be completely remediated. Stewardship is a continuation of site management's regulatory responsibilities under the Comprehensive Environmental Response, Compensation, and Liability Act (CERCLA) and the Resource Conservation and Recovery Act (RCRA). Both CERCLA and RCRA require that possible site remedies be fully assessed in terms 
of their risks, costs, feasibility, and acceptability. Since stewardship will be a remedy or a constituent of a remedy for those sites that cannot achieve complete remediation, stewardship must undergo the same risk, cost, feasibility, and acceptability assessment applied to the "technical" aspects of the remedy, such as pump and treat, incineration, or soil vapor extraction. Although stewardship is inherent in the CERCLA and RCRA requirements, existing regulations and guidance do not comprehensively address stewardship issues, with the result that decision makers may not always fully assess all the risks and costs associated with stewardship.

The objective of the stewardship decisional process model presented in this report is to help decision makers achieve the lowest risk and lowest cost strategy to address contaminated sites. Although stewardship will be the default scenario for many sites, decision makers must assess, understand, and accept all associated risks and costs. Further, decision makers must develop a stewardship program that seeks to keep such risks and costs at the lowest possible level.

The risks and costs of a site stewardship program can be assessed by breaking the program into its component parts, designing the elements of the components, assessing the probability of component failure and the ensuing human health and environmental risk, and determining costs. Stewardship programs will usually have these component parts: containment systems, land use controls, monitoring system, information management system, and organizational system. Assessing the risks and costs of the components requires considerable understanding of contaminant, site, and off-site characteristics as they currently exist and as they will most likely exist in the future. These characteristics will affect component performance.

When the risks and costs associated with developing, implementing, managing, and periodically reassessing the performance of the stewardship program are determined to the best extent possible, they are compared with the risks and costs associated with complete remediation. Decision makers then determine the acceptability of the risks and costs of stewardship. If stewardship is not acceptable, complete remediation might seem more reasonable and acceptable. Decision makers could also choose to undertake some degree of remediation to lessen the risks and costs of stewardship. If stewardship risks and costs were judged acceptable, a stewardship program would be put into effect.

Stewardship programs are not static, however. They will need to be in place and operating effectively for as long as residual contaminants pose a potential risk to humans or the environment. It would be difficult — and possibly unethical for some sites - to create a static stewardship program now that would be expected to last decades or centuries. Contaminants, sites, regulatory programs, conceptions of risk, and the values of communities surrounding sites are all subject to change through time. The components of a stewardship program (e.g., containment systems, monitoring technologies, and land use controls) may not be expected to endure for the length of time they must be in service to provide protection for human health and the environment. For these reasons, a stewardship program must be an iterative process of reassessment and modification. 
An iterative stewardship process consists of a series of stewardship assessment blocks of several years each. The length of the time block would depend upon the severity of the risk posed by the site. As the risk decreases, the length of the time block could increase. At the end of the time block, the effectiveness of the stewardship components would be reassessed by comparing actual performance against performance objectives in light of site, contaminant, and off-site characteristics.

After this reassessment, decision makers would determine whether the stewardship program should be terminated or continued. The decision makers will also need to determine if complete remediation is possible and, if it is, is it reasonable? If the stewardship program will be continued, decision makers must determine whether any new technologies or concepts could be incorporated into the stewardship program to further reduce risks and costs.

Over time, the effectiveness of the stewardship program can be enhanced through application of scientific and technical developments to strengthen the performance of the organizational, containment, monitoring, and information management systems, and the land use controls that are the components of the stewardship program. Research and development should also occur in the areas of risk and cost assessments because they are so crucial to determining whether stewardship is a reasonable alternative to complete remediation. Because of the long time frames associated with stewardship, scientific and technical research and development should be oriented toward technologies, concepts, and processes that are reliable, low-cost, and easily replaceable. 
$\Delta$ 


\section{Section 1 \\ Introduction}

\subsection{Statement of the Problem}

The U.S. Department of Energy (DOE), other federal agencies, state agencies, and the private sector pursuing environmental remediation programs are considering developing stewardship programs at contaminated sites that might not be remediated to the point of allowing unrestricted land use in the immediate future. Deciding to develop, implement, and monitor a stewardship program requires addressing the risks and costs inherent in such programs. A process that lays out the decision points and information and technology needs associated with these risks and costs would assist site managers, regulators, and members of the interested public in making decisions about full remediation versus stewardship programs and the management of such programs. Development of such a process is the subject of this report.

\subsection{Goals and Objective}

The goals for development and use of this decisional process are twofold. The first goal is to help decision makers determine whether a stewardship program would be appropriate for a site and, if so, how to design it. The term "decision makers" is used in a very broad sense to include everyone with an interest in the site, even though they have varying degrees of authority and responsibility for decisions regarding the site. Site decision makers can include personnel responsible for sites, federal and state regulators, and interested members of the public.

The second goal is to lower the risk and cost of stewardship programs by identifying the scientific and technological advances needed in risk assessment, costing, containment, monitoring, information management, land use controls, and organizational systems in order to manage safer and more cost-effective stewardship programs. This information may assist decision makers at the site and national level with stewardship decisions. The objective of the stewardship decisional model is to achieve the lowest risk and lowest cost strategy to address contaminated sites.

\subsection{Background}

Stewardship, as it is used in this report, consists of all activities required to protect human health and the environment from hazards that remain at a previously contaminated site. Stewardship programs are evaluated when it does not seem possible or reasonable to completely remediate a site but the remaining hazard dictates that some uses of the site should be restricted to protect human health and the environment. Restricted use could mean that the land or facility could only be used for certain purposes, such as commercial space or a nature conservancy. Complete remediation would allow unrestricted use of the site; unrestricted use equates to use for residential or agricultural purposes. 
Complete remediation may not be possible because of lack of available technologies to address contaminants (e.g., dense nonaqueous-phase liquids [DNAPL]; complete removal of tank wastes at Hanford and the Savannah River Site). On the other hand, complete remediation may be possible but unreasonable because use of existing technologies would cost too much, expose workers or the public to unacceptably high risk levels, or create extensive collateral ecological damage. Alternatively, existing technologies (e.g., incineration) may not be acceptable to regulators or members of the interested public.

At present, the DOE estimates that 109 of its sites will need stewardship programs in the coming years. The DOE is not alone in needing to consider stewardship programs in light of the inability to completely remediate sites. The Department of Defense (DOD) faces similar concerns at many of its sites with complicated contamination problems. The stewardship issues at these sites, many of which have been ordered to close under the Base Realignment and Closure Act, may be more vexing than those at DOE sites because many DOD sites are located near population centers and could generate greater interest in reuse of the site land and facilities. This situation could require a stewardship program that features robust containment and

\section{Properties Requiring DOE Stewardship}

These properties range from small sites that are not too problematic (e.g., Site A/Plot M in the Palos Forest Preserve in Illinois) to large sites with highly complex contamination problems (e.g., the Oak Ridge Reservation).

Groundwater at approximately 100 of the DOE sites is contaminated with volatile organic compounds (28 sites), metals (29 sites), radionuclides (88 sites), polychlorinated biphenyls (5 sites), or combinations of some or all of these contaminants (thereby accounting for the difference between the total number of sites and the contaminant-specific number of sites). Approximately 71 sites will require stewardship because of surface and/or subsurface soil contamination.

Source: Cleanup to Stewardship, DOE/EM-0466 (DOE 1999). monitoring systems because of the usage of the site.

The Department of the Interior and the General Services Administration may also need to establish stewardship programs of varying intensity at sites for which they are responsible. State agencies and, in some cases, municipalities may have responsibility for ensuring that sites with hazardous constituents are monitored and used only for approved purposes consistent with the risk posed by the site.

Stewardship programs will also be necessary at some private sector sites. These sites could be former National Priority List sites, hazardous waste management sites, or brownfields.

\subsection{Stewardship as a Continuation of Regulatory Responsibilities}

The concept of stewardship — taking responsibility for the residual contamination left after active remediation is completed — is actually embedded in the existing remediation regulatory framework of the Comprehensive Environmental Response, Compensation, and Liability Act (CERCLA) and the Resource Conservation and 
Recovery Act (RCRA). In the CERCLA and RCRA context, stewardship is the "remedy" put in place to address a risk caused by residual contamination. The remedy can consist of containing the contaminants in some form and possibly treating them in some way (e.g., monitored natural attenuation; pump and treat). It can also include restricting use of the area affected by the contaminants, monitoring the site and contaminant activities, and keeping track of activities at the site.

The CERCLA requires decision makers to develop remediation alternatives, assess their risks and costs, and determine their acceptability. For sites that cannot achieve cleanup that results in unrestricted use, stewardship will be either an alternative or a constituent of an alternative (although the word "stewardship" might not be used in remedial investigations, feasibility studies, and records of decision).

If residual contamination will remain on-site as part of the remedy, CERCLA requires five-year reviews to ensure that the remedy is protective of human health and the environment. Stewardship is the process of protecting the site while the residual contaminants present a risk and verifying that the selected remedy is working effectively.

Somewhat similarly, RCRA requires a review of possible corrective measures for contaminated sites and requires 30 years of post-closure monitoring for sites with residual contaminants. The post-closure care period can be extended. Stewardship is the process that occurs during this post-closure care period.

Stewardship is a continuation of a site owner's regulatory responsibilities. Existing regulations and guidance, however, do not comprehensively address the issues associated with stewardship. For this reason, when decision makers are evaluating and selecting remedies that include stewardship, they may not fully assess all associated risks and costs. If this occurs, stewardship may inaccurately appear to be a preferred alternative to complete remediation. Even if complete remediation is not a reasonable alternative and some form of stewardship will be required, it is still incumbent on decision makers to fully evaluate the implications of stewardship and develop stewardship programs that achieve the lowest possible risk and cost.

\subsection{Assumptions}

Several assumptions underlie the stewardship decision process presented in this report:

- The primary objective is to make land available for unrestricted use as soon as possible - This assumption is tempered, however, by the realization that, because of technological, risk, or cost concerns, it may be many years before some property can be made available for unrestricted use. The following assumptions flow from that realization.

- Until property can be made available for unrestricted use, it should be put to its most beneficial use under safe conditions. 
- Some sites will probably never be made available for unrestricted use - Sites such as the Waste Isolation Pilot Plant (WIPP) and disposal sites for high- and lowlevel radioactive wastes would likely be held in government ownership and userestricted because of long-lived radionuclides for as long as there is a functioning government and knowledge of the sites remains.

- Stewardship programs will need to be in place and operating effectively for the length of time that residual contamination creates a potential risk for humans or the environment.

- A stewardship program is an iterative process - Because of the dynamic nature of the contaminants, contaminated media, the site, and the long time frames involved in trying to protect a site from inappropriate uses, it may be difficult (if not impossible) to develop a static plan to protect a site for multiple decades, much less hundreds of years. Stewardship, therefore, is a process that accommodates successive stages of protection, with each stage being based upon assessments of site risks and costs.

- The present state of the components of stewardship programs - containment, monitoring, information management, and organizational systems, and land use controls - does not ensure that stewardship programs will be effective or survive for the length of time they are required to be operational at some sites - Present experience with monitoring and containment technologies is of a fairly limited time frame (roughly 20 years) in contrast to the time frames for which the technologies must be effective in the future. Similarly, our experience with the types of organizational systems and information management systems that will need to be effective over the lifetime of a stewardship program is limited.

- The state of the art of containment and monitoring technologies can be advanced in the relatively near future to strengthen the likelihood of success of stewardship programs - Technical advancement in these areas requires incentives and appropriate resources.

- Technologies allowing complete remediation at some sites and subsequent unrestricted use can be developed in the relatively near future - Development of these technologies will also require appropriate resources and incentives.

- Future generations will likely be in better positions to make remediation and stewardship decisions on the basis of access to greater scientific understanding and more sophisticated technologies - They will, however, need access to information on the nature and type of contaminants on-site, site characteristics, site containment systems, and monitoring data in order to make these decisions. 


\subsection{Definitions}

The definitions that follow are generally used in stewardship literature and discussions. Definitions that are unique to this paper are noted as such.

Stewardship, for the purposes of this study, is defined as all activities required to protect human health and the environment from hazards left remaining at a site.

Complete remediation as used in this report means that all risks have been eliminated or reduced to acceptable levels that allow for unrestricted use.

Unrestricted use means that access to or use of land, resources, or facilities is not limited because of concerns about the presence of residual contamination. Unrestricted use is generally thought of as being compatible with cleanup to residential or agricultural standards.

Restricted use means that use of or access to land or facilities is limited because of the presence of residual contamination. Restricted uses could range from recreational (e.g., parks, wildlife refuge, or nature preserves) to light commercial or industrial purposes.

Site, as used in this report, means a geographic space for which an entity (e.g., DOE, Department of Defense, or private property owner) has authority or responsibility.

Land use controls are developed and implemented to restrict access to or use of land, resources, or facilities in nonapproved ways. These controls can be physical barriers, such as fences or signs, or legal mechanisms, such as zoning, deed notices and easements, leases, government ownership, or permit programs.

Property, as used in this report, refers to land and the facilities attached to it. 
$\Delta$ 


\section{Section 2 \\ Deciding to Pursue a Stewardship Program}

Stewardship programs are considered either when complete remediation is not possible, or when it is possible but does not seem reasonable on one or several counts. In these cases, the risks and costs associated with stewardship programs need to be fully identified, evaluated, and compared with the risks and costs of complete remediation. This comparison is accomplished through the CERCLA or RCRA process of identifying possible remedial actions and assessing their risks, costs, and acceptability (among other factors).

\subsection{Is Complete Remediation Possible?}

If complete remediation were both possible and reasonable, the obvious choice would be to pursue that option and make the site available for unrestricted use, thereby eliminating the need for stewardship. In some cases, however, complete remediation may not be possible because of the existing state of science and technology in the areas of characterization and remediation. In these cases, decision-makers could:

- Evaluate the risk and cost of implementing a stewardship program until a remediation technology becomes available;

- Determine the costs involved in raising the state of science and developing the technologies that could achieve complete remediation; and

- Decide upon the balance between resources committed to the stewardship program and the technology development program.

To answer the question as to whether complete remediation is possible, decision makers must be confident that they have an accurate understanding of site characteristics, site contaminants, and the capabilities and limitations of existing remediation technologies. If such confidence is lacking, the reasonableness of complete remediation in the face of uncertain knowledge should be questioned. Figure 1 illustrates this situation.

\subsection{Is Complete Remediation Reasonable?}

Even though complete remediation may be possible, it may not be reasonable or acceptable if concerns about its side effects outweigh the benefits. These concerns may arise from the risks, costs, or collateral harm associated with complete remediation. These concerns will often be based in objective, quantitative risk and cost assessments, but they can also be heavily influenced by subjective valuations. Regardless of their origin, these concerns can carry enough weight to make complete remediation appear to be an unreasonable option. 


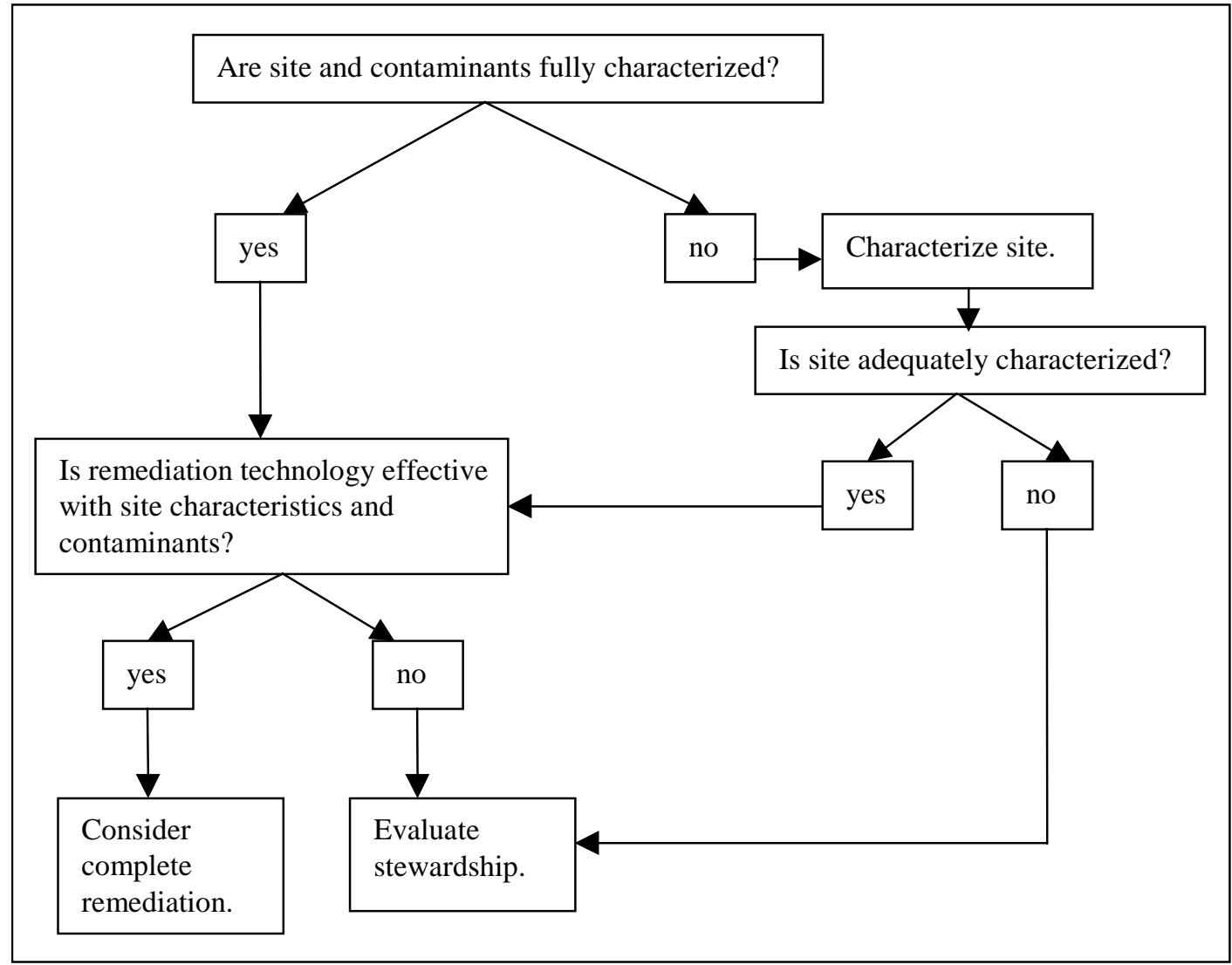

Figure 1 Determining the Possibility of Complete Remediation

\subsubsection{Human Health Risk}

Complete remediation could lead to unacceptable health risks to site or remediation workers or members of the public near to the site. In some cases, it could also result in merely shifting the risk from one site to another. If a site were to be completely remediated, contaminants would either be destroyed or removed. If they were removed, the hazards they pose could result in risk to the transporters, workers at the recipient site, and members of the communities close to the recipient site and along the transportation routes to the site.

\subsubsection{Collateral Damage}

A technology or cleanup strategy capable of achieving complete remediation may do so at the cost of extensive collateral damage to a site's natural and cultural resources. For example, excavating contaminated soil for removal or treatment could lead to the destruction of fragile ecosystems or cultural resources, such as burial grounds or archeologically significant artifacts. 


\subsubsection{Cost}

Complete remediation may simply cost too much to be reasonable. The risk elimination achieved through complete remediation may not be commensurate with the financial costs. Alternatively, the financial investment in completely remediating one site may be more wisely spent at another site that presents a greater risk.

\subsubsection{Acceptability of Remediation Plan}

The perception of unreasonableness of complete remediation could also stem from the concerns regulators and members of the affected public express about the initially selected remediation technology or strategy. For example, some people view incineration as an acceptable and reasonable remediation technology. Some community members and regulators, however, may object to its use because they do not believe the risk assessments associated with incineration. Regulator and community acceptance of remediation technologies is crucial.

Figure 2 expands upon the process for determining whether complete remediation is reasonable. As stated earlier, reasonability and acceptability can be objective or subjective beliefs that side effects outweigh the benefits of complete remediation.

\subsection{Is Stewardship Reasonable?}

If complete remediation does not appear possible or reasonable, decision makers will need to evaluate the strengths and weaknesses of a stewardship program applicable to their site. Stewardship will usually include some degree of site remediation, some form of contaminant containment, and some use restrictions to prevent exposure to residual contaminants. The greatest factors to be assessed in evaluating a stewardship program are the risks and costs associated with its component parts. Figure 3 lays out the basic process for making decisions about stewardship. 


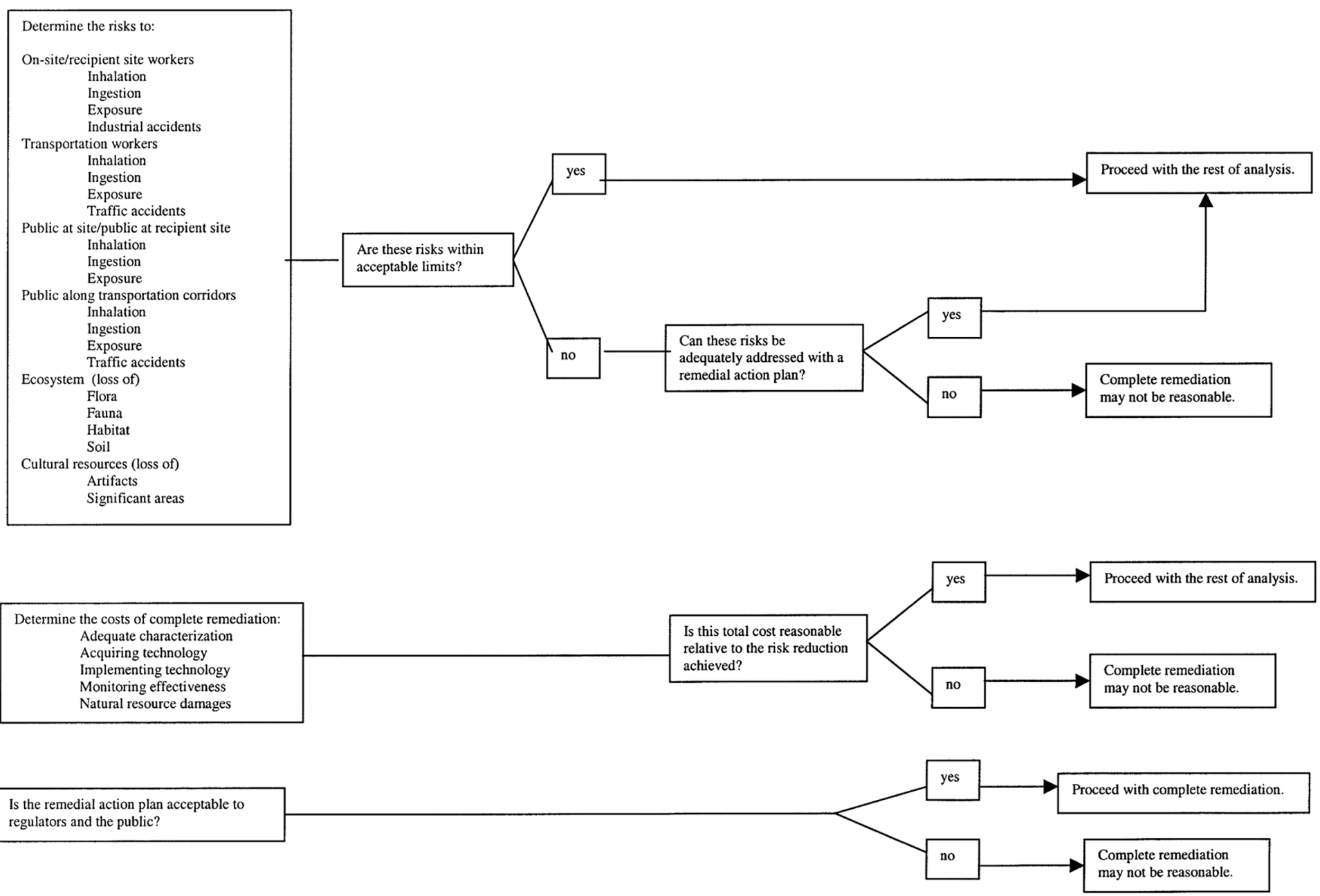

Figure 2 Determining the Reasonability of Complete Remediation 


\section{Basic Decision Process}

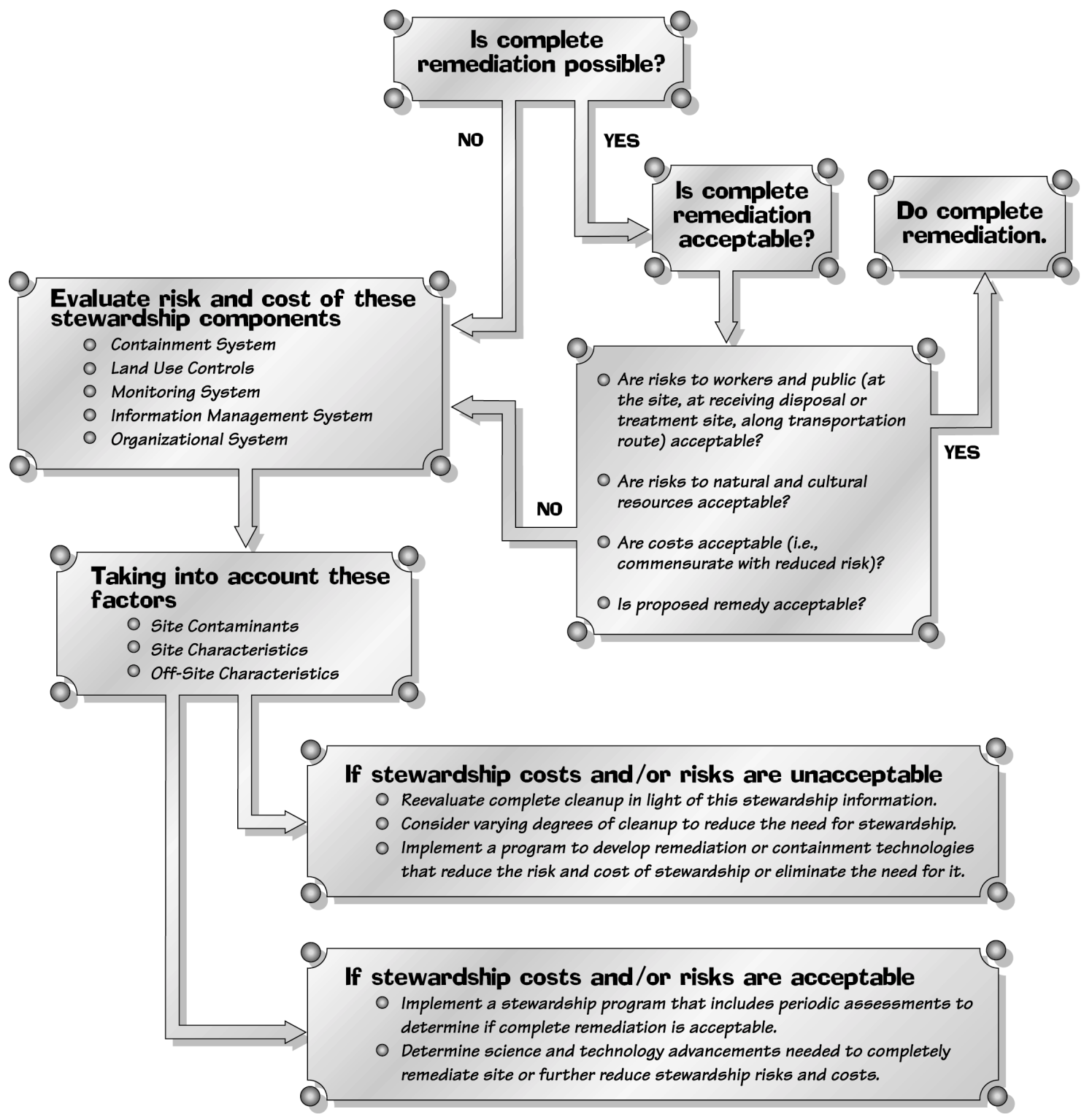

Figure 3 Basic Decision Process 
$\Delta$ 


\section{Section 3 \\ Conceptualizing a Stewardship Program}

One of the assumptions stated earlier is that a stewardship program is an iterative process. It is hard to imagine creating a static stewardship program now that would be expected to last decades or centuries. For many sites, it may be unrealistic and possibly unethical to do so. Contaminants, sites, regulatory programs, conceptions of risk, and the values of communities surrounding sites are all subject to change through time. Engineered containment systems, monitoring technologies, and land use controls may not be expected to endure for the length of time they must be in service to provide protection for human health and the environment. For all these reasons, a stewardship program must be an iterative process of reassessment and modification.

\subsection{Components}

The components of a stewardship program - a contaminant containment system, land use restrictions, a monitoring system, an information management system, and an organizational system - will need to continue until the site can be released for unrestricted use, although they may vary in intensity during the stewardship program. For example, a contaminant-monitoring plan may need to be very vigorous in the early stages of the stewardship program, but may be considerably scaled back as the contaminant source degrades. The basis for this reduced monitoring would be the results of a periodic reassessment of the risks and costs associated with the stewardship program. These periodic reassessments turn stewardship from a static project into an iterative process.

\subsection{Assessment}

An iterative stewardship program could be conceived of as a series of stewardship assessment blocks of several years each, with the program containing enough blocks to protect the site as long as protection is required. The length of the time block would depend upon the severity of the risk posed by the site and the resulting pressure to periodically reassess the effectiveness of the stewardship program put in place to control that risk. As the risk posed by the site decreases, the length of the time block could increase.

The status of the stewardship components relative to their performance objectives and the characteristics of the site, the contaminants, and off-site areas would be assessed at the end of each block in order to measure the effectiveness of the program in terms of risk protection and cost effectiveness. After this assessment, decision makers would again need to determine whether complete remediation is possible and, if it is possible, is it reasonable (see Figure 3). If complete remediation is neither possible nor reasonable, the decision makers would modify the stewardship program to address any identified weaknesses and incorporate any new technologies that could reduce the risk and/or cost 
of the program. A decision would also be made as to the length of the next time block to determine when the next stewardship assessment would be done.

Figure 4 portrays a stewardship program conceptualized as an iterative process built upon periodic assessments. When a risk assessment indicates that the site can be released for unrestricted use, the component parts of the program would cease except for the information management system. The findings and documentation that support release of the site for unrestricted use, as well as select information gathered during the stewardship program, should be retained for historical purposes after stewardship has ceased.

Figure 4 only partially conveys two of the dynamic features of stewardship programs. First, it does not demonstrate that the rigorousness of a component can change through time as a function of either greater or lesser risk that must be addressed. Second, it conveys the components as parallel rather than integrated and interrelated processes.

The monitoring system should be designed to assemble data on the performance of the organizational system, the containment system, land use controls, and the characteristics of the contaminant, the site, and off-site areas. The information management system gathers all this information, stores it, and permits its analysis and dissemination. The organizational system ensures proper functioning of the monitoring system and the information management system, operation and maintenance of the containment system, enforcement of the land use controls, and assessment of monitoring data.

Conceptualizing stewardship as an iterative process with integrated and interrelated components allows decision makers to think realistically about the limitations and possibilities associated with monitoring, information management, containment, and organizational systems, and land use controls as they implement, monitor, and assess a stewardship program. 


\section{A Stewardship Program is an Iterative Process}
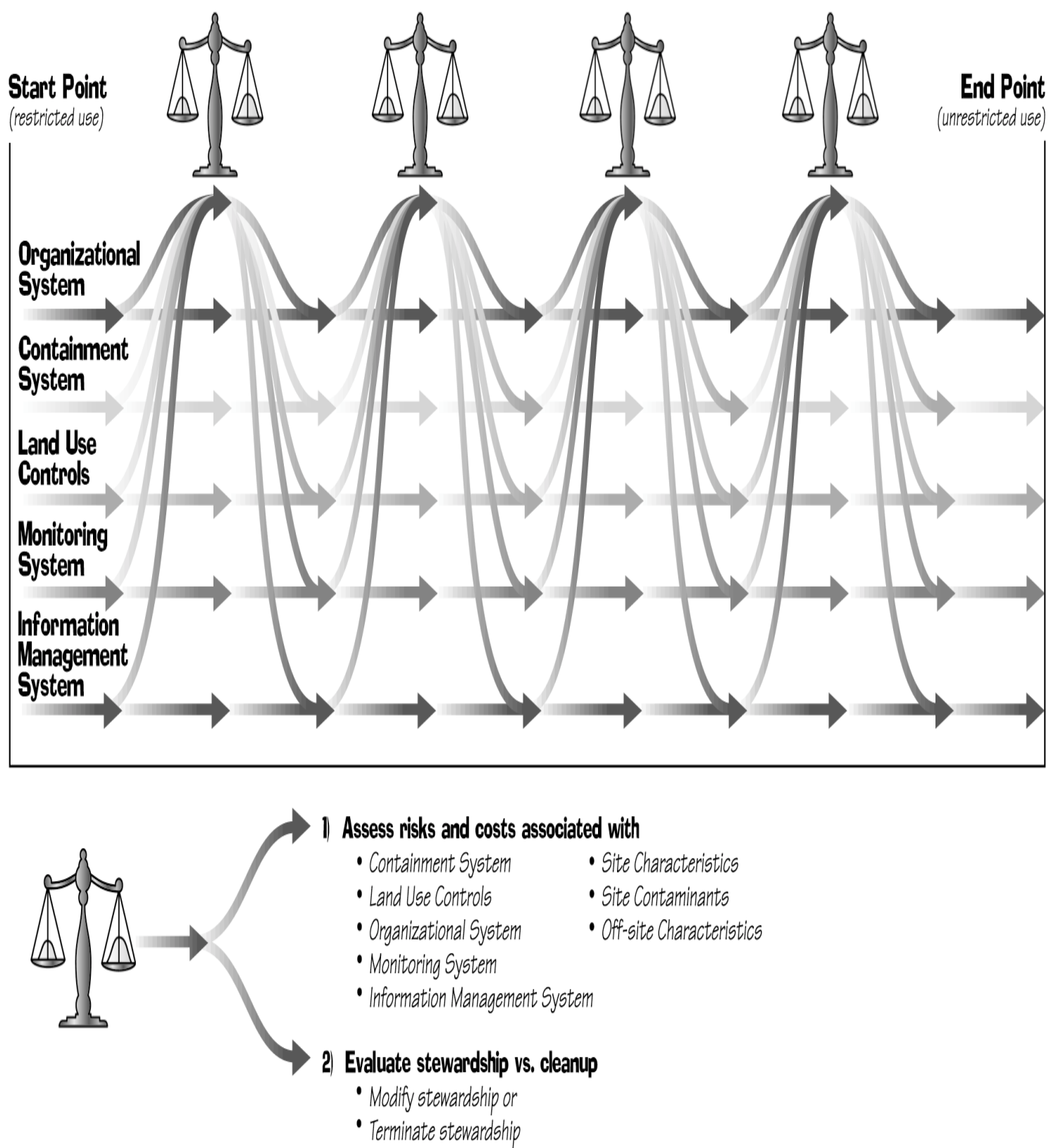

Figure 4 A Stewardship Program Is an Iterative Process 
$\Delta$ 


\section{Section 4 \\ Evaluating a Stewardship Program as an Alternative to Complete Remediation}

\subsection{Evaluation of Risks and Costs}

Two questions frame the process for evaluating the risks and costs of a stewardship program: (1) "How long will the contaminants of concern pose a risk?" and (2) "Can the contaminants be contained, monitored, and access-restricted for that length of time?" The first question relates to the characteristics of the site, its contaminants, and off-site characteristics and is normally answered through the development of a conceptual site model. The contaminants, the site, and off-site conditions need to be well-characterized in order to identify the following conditions that need to be addressed through the stewardship program:

- Primary contamination sources;

- Primary release mechanisms;

- Secondary sources (typically soil, sediment, surface water, groundwater, air);

- Secondary release mechanisms;

- Contaminated media;

- Primary exposure rates; and

- Potential receptors.

Even though sites may have similar contaminants of concern (e.g., metals and radionuclides), exposure pathways will vary considerably depending on site and off-site characteristics. The relatedness of the characteristics of contaminants, sites, and off-site areas to the characteristics of a stewardship program is described in Figure 5.

The second question addresses the characteristics of the component parts of a stewardship program. The stewardship program proposed to

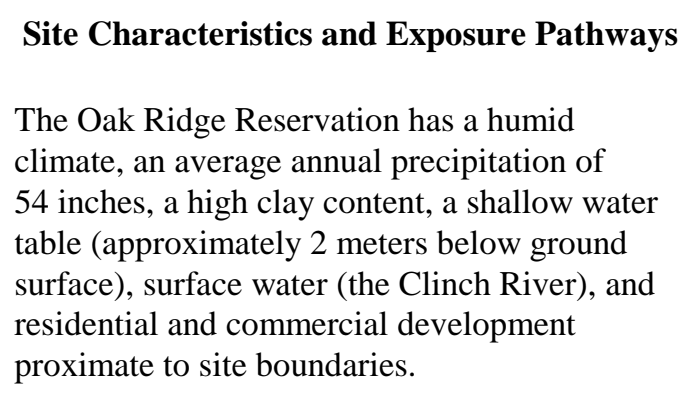
climate, an average annual precipitation of 54 inches, a high clay content, a shallow water table (approximately 2 meters below ground surface), surface water (the Clinch River), and residential and commercial development proximate to site boundaries.

The exposure pathways at Oak Ridge are dramatically different than those found at the Idaho National Engineering and Environmental Laboratory, which has a semiarid climate, average annual rainfall of 8.5 inches, basalt over $75 \%$ of its surface, a fairly deep water table (approximately 50 meters below ground surface), no surface water, and no human populations proximate to the site.

Geologic and climatic information source: Groundwater and Soil Cleanup: Improving Management of Persistent Contaminants (National Research Council 1999). 


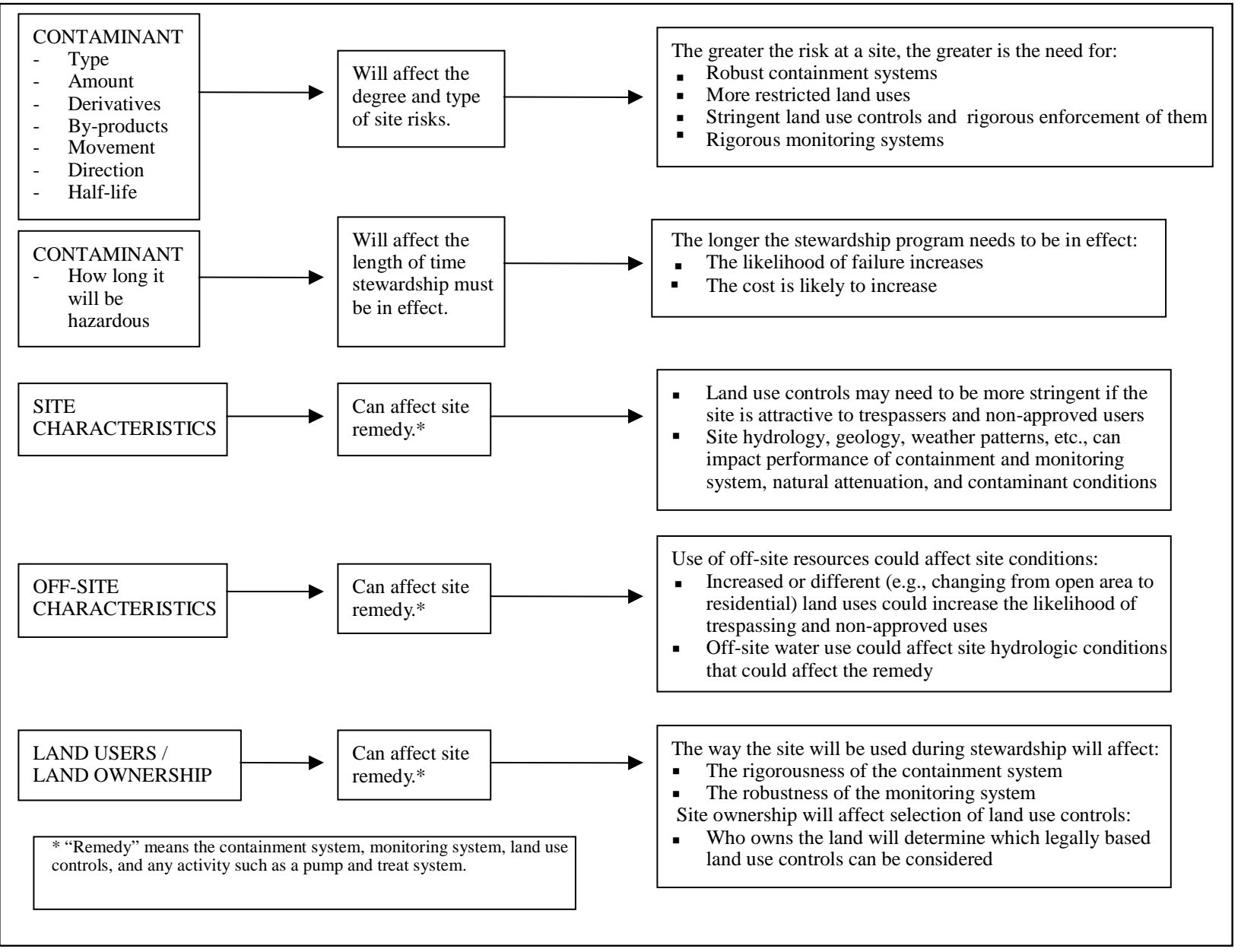

Figure 5 Site Information Needed to Evaluate Risk and Cost of a Stewardship Program

address site risks can be evaluated by breaking it into its component parts, determining their costs, and assessing the probability of their failure and the ensuing human health and environmental risks. Stewardship programs will usually have these component parts: containment systems; land use controls; a monitoring system; an information management system; and an organizational system. The following sections briefly describe the desired attributes of these components and their risks and costs as they relate to stewardship programs. Figure 6 provides additional detail on the information needed to evaluate risks and costs. This chapter ends with an example of how site stewardship plans could be designed in order to evaluate their associated risks and costs. 


\section{Containment Systems:}

- Contaminants (including by-products and derivatives) and their volume and life expectancy;

- Life expectancy of available containment systems under site conditions;

- Performance of similar containment systems under similar conditions;

- Reasonable scenarios that could lead to failure of the system;

- Expected state of the contaminants at the point the containment system will reach its obsolescence;

- Impediments, associated with the containment system or the site, to replacing the system when it becomes obsolete;

- Exposures that could result from containment failure or obsolescence;

- Expected costs of implementing, monitoring, and maintaining the system; and

- Expected costs of implementing, monitoring, and maintaining any replacement containment system.

\section{Land Use Controls:}

- Expected future uses;

- Expected future users of the site;

- Expected future owner(s) of the site;

- Land use controls that could be put into effect, their chances for success, and the costs of implementing and enforcing them through time;

- Time periods that land use restrictions and accompanying use controls are expected to be in effect;

- Expected changes in land use of areas contiguous to the site that could affect projected future uses;

- The party or parties with responsibility for implementing, monitoring, enforcing, and modifying the land use controls; and

- The authority and capability of the responsible party or parties to complete their land use control responsibilities.

\section{Monitoring Systems:}

- Contaminants (including by-products and derivatives) to be monitored;

- Life expectancy of the contaminants being monitored;

- Life-cycle of the contaminants under site conditions (monitoring systems will need to both detect and monitor any derivative products);

- Containment systems that must be monitored;

- Characteristics of the containment system that could impede effective monitoring;

- Land use controls that must be monitored;

- Characteristics of land use controls that could inhibit efficient and effective monitoring;

Figure 6 Information Needed to Evaluate the Risks and Costs Associated with Stewardship Components 
- Site or contaminant characteristics that could impede effective monitoring now and in the future;

- Advantages and limitations of existing monitoring technologies;

- Advantages and limitations of existing analytic capabilities;

- Costs of applicable technologies and analytical services;

- Reasonable failure scenarios of the monitoring system and the likely results of such failures;

- Expected costs of designing, implementing, re-evaluating, and modifying the monitoring systems; and

- Expected costs of analyzing and managing monitoring data.

\section{Information Management Systems:}

- Compatibility of existing information systems with the projected management information system needs;

- Information to be gathered as necessary background for the stewardship program;

- Availability and usefulness of existing information that will be needed in the information management system;

- Information to be gathered and stored while the stewardship program is in place;

- Determination as to which people will need information derived from the information management system;

- Method for conveying information to the appropriate people;

- Expected costs of technologies used in the information management system throughout the life of the stewardship program; and

- Reasonable failure scenarios of the information management system and their likely outcomes.

\section{Organizational Systems:}

- Likely scenarios that would result in failure of the organizational system; and

- Cost of technical, administrative, and support staff needed to implement and maintain the stewardship program.

\section{Figure 6 (Cont.)}

\subsection{Containment Systems}

\subsubsection{Overview}

Containment systems are relied upon to restrict the release of contaminants into the environment. For the purposes of this report, the term "containment system" can include engineered as well as natural systems.

Containment systems can be engineered systems such as caps, barriers, tanks, barrels, or disposal cells. However, there will be sites at which containment will consist of leaving contaminants in the soil or groundwater with the expectation that the control of releases to the environment will be accomplished through land use controls or a combination of land use controls and natural attenuation. For example, the containment system for contaminated sediment in a riverbed would be the river and the sediment itself. The containment system could be enhanced with a prohibition against dredging. 


\subsubsection{Attributes of Containment Systems}

The primary attribute needed for containment systems used in stewardship programs is that they be designed to last for as long as the contained contaminant presents a risk. If engineered systems cannot be so designed, then provisions should be made for how and when they will be replaced or modified or how the contaminants will be treated when the containment system fails. If reasonable assurances cannot be given that natural containment systems will survive the contaminants they contain, contingency plans should be developed to address failure of the containment system.

Containment systems must also be capable of being monitored in reliable, yet cost-effective, ways. They should also feature low maintenance costs and reasonable implementation costs.

Containment systems should

- Survive the risk potential of contaminants

- Have failure contingency plans

- Be capable of being monitored

- Be cost-effectively maintained.

\subsubsection{Evaluating the Risks and Costs Associated with Containment Systems}

Workers, the public, or the environment could be exposed to hazardous contaminants if the containment system fails before its projected life expectancy has been reached and the contaminants still pose a risk. Harmful exposures could also arise if the containment system life expectancy is less than the time period for which the contaminants will remain hazardous, the system's life expectancy has been reached, and no efforts have been made to either recontain the contaminants or completely remediate the site.

The likelihood that the containment system will fail before its projected life expectancy should be evaluated, and the potential risk and cost consequences of that failure to human health and the environment should be assessed. Similarly, the risk (human health and environmental) associated with the failure to recontain contaminants or remediate them when the containment system has become obsolete should also be assessed.

The costs of remedying any harm that ensues from the failure of the containment system or from its obsolescence should be calculated as part of the likely cost of the stewardship program. The other costs of containment systems that must be calculated are those associated with the design, implementation, maintenance, monitoring, and replacement of the system.

\subsection{Land Use Controls}

\subsubsection{Overview}

Land use controls are put in place as part of a stewardship program to restrict access to or use of land, resources, or facilities with residual contamination. Some contaminated areas and facilities may warrant completely restricted use, but others may still have 
valuable potential for reuse if appropriate safeguards are in place to ensure that only approved uses occur. Approved uses would depend on the acceptable level of risk and cost associated with the reuse.

Land use controls are used either to restrict all use or limit it to only approved uses. For example, use of a parcel of land with considerable soil contamination may be within acceptable risk and cost ranges if it is covered with asphalt and used only as a parking lot for light-commercial use. In this example, the land use control could be a lease. The lease would stipulate the conditions under which the parking lot could be used, the physical characteristics of the lot (e.g., depth of the asphalt cover; breadth and length of acceptable cracks in the asphalt), and those responsible for ensuring that those characteristics are achieved and maintained.

Land use controls can be legal mechanisms such as easements, zoning, permit programs, or federal,

Institutional Controls

Institutional controls are often thought of as legal or administrative authorities or tools used to restrict land or resource use, as opposed to engineered systems designed to restrict use.

The types of institutional controls that could be used at a site will depend upon who owns the land.

The effectiveness of institutional controls depends greatly on such factors as their legal basis and enforceability.

state, or local government ownership. These mechanisms are often referred to as institutional controls. Land use controls can also be engineered barriers, such as signs or fences.

\subsubsection{Attributes of Land Use Controls}

Land use controls must endure for the length of time the land use restriction must be observed. They must also be capable of being reliably and cost-effectively implemented and monitored. Land use controls must also be enforceable. In the parking lot example described above, it is vitally important that someone have the legal

Land use controls should

- Endure

- Be implementable

- Be monitorable

- Be enforceable authority and responsibility to enforce the terms of the lease. Failure to enforce the use restriction could result in contaminant exposure.

The appropriateness and effectiveness of land use controls that have a legal basis will depend heavily on applicable laws, regulations, case law, policy, and the authority and infrastructure of the responsible parties. For example, local governments receive their authority to zone from the state, but they may vary considerably in the availability of resources needed to make and enforce zoning decisions. The effectiveness of zoning as a land use control may be highly dependent upon the authority and resources of the local zoning board. 
Land use controls do not necessarily waive the liability of the party responsible for the residual contamination. This situation makes it even more imperative that land use controls be carefully selected and monitored.

\subsubsection{Evaluating the Risks and Costs Associated with Land Use Controls}

Federal Agencies are Responsible for Institutional Controls on Transferred Property

"Even if implementation of the institutional controls is delegated in the transfer documents, the ultimate responsibility for monitoring, maintaining and enforcing the institutional controls remains with the lead federal agency responsible for the cleanup."

Source: Institutional Controls and Transfer of Property under CERCLA Section 120(h)(3)(A), (B) or $(C)$ (U.S. Environmental Protection Agency 2000)

Land use controls could fail, unapproved uses of land or facilities could occur, and harm to human health and the environment could ensue. An evaluation should be conducted to assess how land use controls could fail (e.g., a use restriction is not properly recorded in a deed), the probability of their failure, and the potential risks and costs of such failure. The costs of land use controls are those associated with their design, implementation, monitoring, enforcement, and modification.

\subsection{Monitoring Systems}

\subsubsection{Overview}

Procedures and methods will be needed to monitor the performance of all the components of the stewardship program. Monitoring wells, sensors, or visual inspections can be elements of a monitoring plan for containment systems. Visual inspections could be used to monitor the effectiveness of such land use controls as fences, deed restrictions, zoning prohibitions, or permit requirements, and self-audit reports could be used to monitor leases.

The organizational system must be monitored to ensure that management and assessment responsibilities are being completed. The information management system would be monitored to ensure that relevant data are collected, and appropriately stored and managed, and that collected information has not been corrupted or lost. Provisions will also need to be made to periodically evaluate the monitoring procedures and methods themselves to determine whether they are operating efficiently and effectively.

In addition to measuring performance of the components, a monitoring system should also monitor changes in the contaminant source, the contaminated media, the site, and the area surrounding the site. Monitoring these changes is important because their status can severely impact the nature and effectiveness of the stewardship program. For example, drinking water supply wells installed off-site after a groundwater pump and treat system has been put in place on-site to restrict movement of a contaminated plume could affect the water table in such a way as to jeopardize the effectiveness of the pump and treat system. Visual monitoring of the uses of land surrounding the site might detect 
the well digging, or analytical results from contaminant monitoring could indicate the failure or diminished effectiveness of the barrier. As a result of such monitoring activities, site managers could determine the need to reassess and possibly redesign the containment or land use controls systems.

\subsubsection{Attributes of Monitoring Systems}

The key requirement of monitoring systems is the reliable and valid measurement of the performance of stewardship components, contaminant activity, and relevant site and off-site characteristics.

Obviously, monitoring systems must be designed to be functional for the life expectancy of contaminants and containment systems (and their replacements)

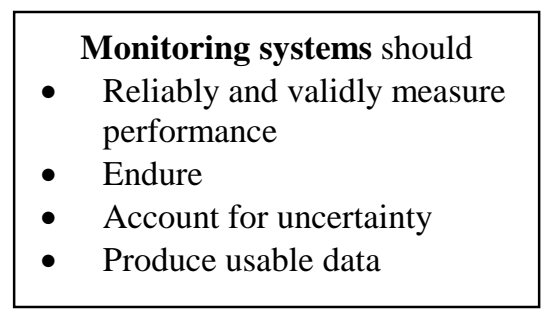
and for the time period the land use controls are required to be in effect.

Monitoring plans should be designed to take into account the uncertainties associated with the contaminants and their derivatives, the physical characteristics of the site, and reliable but cost-effective monitoring technologies and analytical capabilities.

Uncertainties that can be identified may be addressed through proper contingency planning. The monitoring system should include "triggers" - performance indicators that reveal the need to modify the containment system, the land use controls, the organizational system, or the monitoring plan itself. The triggers reflect decision rules that describe the conditions that indicate the need for change, as well as the contingent plans that should be put into operation when such conditions arise (DOE 1998).

Monitoring plans should also be designed so that monitoring data are usable for refining models, communicating containment effectiveness and contaminant status, and

\section{Recognizing Uncertainty and Building Contingencies into Monitoring Plans}

The CERCLA Record of Decision developed to address on-site and off-site tritium groundwater contamination at Brookhaven National Laboratory includes these triggers and contingencies:

1. Evaluate the need to reactivate the Princeton Avenue interim removal action (a pump and recharge system) if tritium concentrations exceed $25,000 \mathrm{pCi} / \mathrm{L}$ at the Chilled Water Plant Road;

2. Reactivate the Princeton Avenue interim removal action if tritium concentrations exceed $20,000 \mathrm{pCi} / \mathrm{L}$ at Weaver Drive; and

3. Install low flow extraction systems in the most concentrated area of tritium contamination near the High Flux Beam Reactor and near Temple Place if concentrations exceed $2,000,000 \mathrm{pCi} / \mathrm{L}$ in front of the Reactor.

"As these extraction wells operate, extensive monitoring will occur to evaluate the effect of extraction locally as well as on the entire plume. Because of the inherent uncertainties of predicating plume behavior based on groundwater modeling, the actual monitoring data will be evaluated and used to help determine whether continued operation of the extraction system is needed to achieve the cleanup objectives."

Source: Brookhaven National Laboratory Operable Unit III Record of Decision (Brookhaven 2000). 
guiding future remediation and monitoring decisions. Monitoring plans for land use controls should address the uncertainties and reasonable failure scenarios associated with the controls. For example, the periodicity of monitoring the stability of a fence barring use of a stream should be much greater for a site that is highly attractive to swimmers than it would be for a less attractive, very remote site. As another example, the effectiveness of zoning or permit programs would need to be monitored more frequently at a site that is facing encroaching residential or commercial development.

\subsubsection{Evaluating the Risks and Costs Associated with Monitoring Systems}

An unplanned and harmful release of contaminants into the environment could occur if monitoring procedures and methods for containment systems fail and there is no timely warning of the likelihood of that failure. Monitoring plans for land use controls could fail if they were inadequately designed or funded and therefore were not capable of overseeing the effectiveness of the controls. The possibility of these failures should be examined along with the human health and environmental risk associated with these failures. The costs of monitoring systems include their design, implementation, maintenance, data management and assessment, reassessment in light of ineffectiveness or more effective technologies or methods, and necessary modification.

\subsection{Information Management Systems}

\subsubsection{Overview}

Information management systems gather, store, and disseminate information associated with the site and its stewardship program. The information that pertains to a stewardship program can include documents and reports, technical data sets, and communications; it may exist as both hard copy materials and an electronic format. A stewardship information system is composed of the information that is being preserved; the hardware/software infrastructure used to gather, store, and disseminate information; the associated protocols and processes; and the organizational infrastructure that maintains the system.

A well-conceived stewardship information management system is essential to an effective long-term stewardship program for several reasons. Legacy information that is readily available to stakeholder communities in an accessible and easily understood format can be instrumental in preventing misunderstandings or misconceptions about a site from developing during the long time periods stewardship will need to be in effect. For example, the Chariot Site in Alaska was reopened a mere 7 years after its closure because of stakeholder concerns that could have been allayed if legacy information was available.

Information management systems are the key to organizing, interpreting, and disseminating monitoring information in a way that identifies potential risk or performance concerns before they become serious. In the event that problems do arise 
that require attention, access to the original characterization data, system design information, and long-term monitoring data may significantly reduce the resources needed to correct the situation. Several million dollars was spent in recharacterizing Site A (in Illinois) after wastes were unexpectedly discovered. The high cost was due, in part, to the unavailability of data collected to support site closure in the 1970s.

Finally, stewardship programs are iterative processes driven by periodic reassessments of site stewardship costs and risks. These reassessments will be expedited if an information management system can be relied upon to provide reliable data on contaminant states, as well as performance and costs for the containment system and land use controls.

\subsubsection{Attributes of Information Management Systems}

Effective stewardship information management systems will be lean and cost efficient. They will have procedures and logic in place for identifying and capturing the legacy and emerging information relevant to the stewardship program. This

Information management systems should

- Capture relevant information

- Preserve information

- Disseminate information in userappropriate formats information can include raw data streams from monitoring locations, derived information that represents modeling or data interpretation results, and results of the periodic reassessments of the stewardship program.

Long-term stewardship information management systems will be able to manage, preserve, and disseminate information in a wide variety of formats, including paper documentation; hardcopy maps, drawings, and photographs; and electronic information. Information will be transparent and available to a wide variety of users (e.g., regulators, modelers, risk and cost assessors, and members of the public) in ways that satisfy their information needs (e.g., summary tables showing contaminant movement trends, data streams, and three-dimensional visuals depicting an interpretation of actual monitoring data).

The information in the system and the system itself cannot be proprietary to any one organization. They must be transferable to and usable by subsequent organizations with responsibility for the stewardship program.

\subsubsection{Evaluating the Risks and Costs Associated with an Information Management System}

The risks that could ensue from a stewardship information management system are related to missing, lost, corrupted, or inaccessible data that could lead decision makers to reach unwarranted conclusions about contaminant and containment decisions. These conclusions could lead to releases of contaminants into the environment, failure to detect releases, or the inability to accurately assess the risks associated with the site. Over time, 
missing, incomplete, corrupted, or inaccessible information could lead to perceived risks and concerns within the stakeholder community that, although unwarranted, would require a response. Without a reasonably accurate risk assessment, or with a misinformed stakeholder community, there may be no technical basis or stakeholder support for modifying or terminating the stewardship program. The costs of information management systems are associated with their development, implementation, maintenance, execution, and modification in light of emerging technologies.

\subsection{Organizational System}

\subsubsection{Overview}

The organizational system is the infrastructure of personnel, policies, and processes that support the implementation, management, and periodic reassessment of the entire stewardship program. Its structural or organizational design (e.g., federal or state government agency, quasi-governmental agency, or contractor operated) must be conducive to carrying out the stewardship mission.

\subsubsection{Attributes of Organizational Systems}

The organization entrusted with managing the stewardship program must have the authority, responsibility, and incentives to carry out its obligations. The personnel must have the skills to implement the stewardship program, understand the significance of monitoring data and risk assessments, oversee periodic reassessments of the stewardship program, and determine the possibilities for complete

Organizational systems should have

- Authority

- Responsibility

- Incentives

- Proper skill mix of personnel remediation. The organization's policies and processes must promote, rather than impede, implementation and execution of the components of the stewardship program.

\subsubsection{Evaluating the Risks and Costs of Organizational Systems}

Human and environmental risk could arise if the organizational system's support of the stewardship program becomes a low priority or diminishes through time. This situation could develop for several reasons: change in institutional priorities, budget problems that cause the organization to cut back on its activities, complacency of personnel, or an inappropriate skill mix of people in the organization. If organizational support for the stewardship program is weakened or allowed to wither, land use controls and containment systems could be breached, monitoring results could be misinterpreted or ignored, and information management systems could become ineffective. Any or all of these events could severely compromise the integrity of the stewardship program. The costs of a stewardship support organization arise from the staff and support systems needed to implement, execute, and assess the stewardship program. 


\subsection{Designing Stewardship Programs to Facilitate Evaluation}

To evaluate whether stewardship is reasonable or acceptable for a site, decision makers will need to design a site stewardship program — the base program — and variations of it, as needed, to address issues affecting the site. Table 1 portrays such a base plan and its variations in very broad terms.

The base program, for example, may call for a minimum of contamination reduction (i.e., active remediation activities to treat contamination) and reliance on a cap and land use controls and monitored natural attenuation to prevent exposures for 100 years (the period the contaminants are expected to be hazardous). A preliminary evaluation of the risks and costs of the base plan indicates that both are unacceptably high, which leads to the design of Variation 1.

Variation 1 of the base program includes more contamination reduction to remove site hot spots, which then reduces the period that the site will be harmful from 100 years to 40 years. The cap, land use controls, and associated stewardship activities would then need to be effective for only 40 years, which considerably lowers the risks and costs. However, the performance of the technology considered for Variation 1 is somewhat unpredictable given site and contaminant characteristics, and the degree of uncertainty associated with its use is unacceptable. As a result, Variation 2 is designed.

Variation 2 is based on the assumption that the technology considered under Variation 1 would be successful at the site if further research and testing were pursued. Although the cost of this research and testing may be high, it may be offset by reduced stewardship activity risks and costs if the land use is highly restricted (e.g., federal government use only) until the technology is usable.

After the risks and costs of a stewardship program have been assessed to the maximum degree possible, decision makers have two options:

1. Determine that complete remediation is reasonable compared with the risks and costs associated with a stewardship program; or

2. Implement the stewardship program that has been evaluated (i.e., protect human health and the environment until the site can be released for unrestricted release), and periodically reassess it until new technologies are available that allow for complete remediation or until the contaminants are no longer hazardous.

The following chapters describe the processes applicable to implementing and monitoring, assessing, modifying, and terminating stewardship programs. 


\section{Table 1 Designing and Evaluating Potential Stewardship Programs}

\begin{tabular}{|c|c|c|c|}
\hline Element & Base Plan & Variation 1 & Variation 2 \\
\hline $\begin{array}{l}\text { Contamination } \\
\text { Reduction }\end{array}$ & $\begin{array}{l}\text { Minimum contamination } \\
\text { reduction to allow reuse of } \\
\text { certain areas; residual } \\
\text { contaminants hazardous for } \\
100 \text { years; natural attenuation } \\
\text { is remedy for groundwater }\end{array}$ & $\begin{array}{l}\text { Hot spot removal to allow } \\
\text { restricted use of entire area; } \\
\text { residual contaminants } \\
\text { hazardous for } 40 \text { years; natural } \\
\text { attenuation is remedy for } \\
\text { groundwater }\end{array}$ & $\begin{array}{l}\text { Invest in development of } \\
\text { technology for hot spot removal in } \\
10 \text { years; defer minimum } \\
\text { decontamination of Base Plan } \\
\text { until hot spots are removed; } \\
\text { natural attenuation remedy for } \\
\text { groundwater }\end{array}$ \\
\hline Land Use & $\begin{array}{l}\text { Commercial/industrial with } \\
\text { restrictions on water-well } \\
\text { drilling and excavations below } \\
4 \text { feet in certain areas }\end{array}$ & $\begin{array}{l}\text { Commercial/industrial with } \\
\text { restriction on water-well drilling }\end{array}$ & $\begin{array}{l}\text { Federal government use only until } \\
\text { hot spots removed and minimum } \\
\text { decontamination completed; land } \\
\text { then used as under Variation } 1\end{array}$ \\
\hline Land Use Controls & $\begin{array}{l}\text { Land transferred to private } \\
\text { party; local government to } \\
\text { impose zoning, well-drilling } \\
\text { and excavation permit } \\
\text { requirements; federal } \\
\text { government retains easement } \\
\text { to monitor site }\end{array}$ & $\begin{array}{l}\text { Land transferred to private } \\
\text { party; local government to } \\
\text { impose zoning, and well-drilling } \\
\text { permit requirements; federal } \\
\text { government retains easement to } \\
\text { monitor site }\end{array}$ & $\begin{array}{l}\text { Land held by federal government } \\
\text { until hot spots removed and } \\
\text { minimum decontamination } \\
\text { achieved; then managed as under } \\
\text { Variation } 1\end{array}$ \\
\hline Containment & $\begin{array}{l}\text { Cap over several hot spots; } \\
\text { geologic containment of } \\
\text { groundwater }\end{array}$ & $\begin{array}{l}\text { Geologic containment of } \\
\text { groundwater }\end{array}$ & $\begin{array}{l}\text { Geologic containment of } \\
\text { groundwater }\end{array}$ \\
\hline Monitoring & $\begin{array}{l}\text { Components, site, off-site, } \\
\text { contaminants for } 100 \text { years }\end{array}$ & $\begin{array}{l}\text { Components, contaminants, } \\
\text { site, off-site for } 40 \text { years }\end{array}$ & $\begin{array}{l}\text { Components, contaminants, site, } \\
\text { off-site for } 40 \text { years }\end{array}$ \\
\hline $\begin{array}{l}\text { Information } \\
\text { Management }\end{array}$ & $\begin{array}{l}\text { Site characterization and } \\
\text { monitoring data gathered and } \\
\text { assessed for } 100 \text { years }\end{array}$ & $\begin{array}{l}\text { Site characterization and } \\
\text { monitoring data gathered and } \\
\text { assessed for } 40 \text { years }\end{array}$ & $\begin{array}{l}\text { Site characterization and } \\
\text { monitoring data gathered and } \\
\text { assessed for } 40 \text { years }\end{array}$ \\
\hline $\begin{array}{l}\text { Organizational } \\
\text { System }\end{array}$ & $\begin{array}{l}\text { Staff and funding to assess } \\
\text { and modify stewardship for } \\
100 \text { years }\end{array}$ & $\begin{array}{l}\text { Staff and funding to assess and } \\
\text { modify stewardship for } 40 \text { years }\end{array}$ & $\begin{array}{l}\text { Staff and funding to assess and } \\
\text { modify stewardship for } 40 \text { years }\end{array}$ \\
\hline Risk Estimates & $\begin{array}{l}\text { High risk of contaminant } \\
\text { release due to uncertainty } \\
\text { about: } \\
\text { - cap life expectancy } \\
\text { - stability of zoning, well- } \\
\text { drilling, excavation permit } \\
\text { programs for } 100 \text { years } \\
\text { - reliability of monitoring for } \\
100 \text { years } \\
\text { - organizational ability to } \\
\text { oversee stewardship for } 100 \\
\text { years }\end{array}$ & $\begin{array}{l}\text { Medium risk of contaminant } \\
\text { release due to uncertainty about: } \\
\text { - stability of zoning, well-drilling } \\
\text { permit program for } 40 \text { years } \\
\text { - reliability of monitoring over } \\
40 \text { years } \\
\text { - organizational ability to oversee } \\
\text { stewardship for } 40 \text { years } \\
\text { - high risk of contaminant } \\
\text { reduction technology being } \\
\text { unsuccessful under existing } \\
\text { conditions }\end{array}$ & $\begin{array}{l}\text { Medium risk of contaminant } \\
\text { release due to uncertainty } \\
\text { about: } \\
\text { - stability of zoning, well-drilling } \\
\text { permit program for } 30 \text { years } \\
\text { - reliability of monitoring over } \\
40 \text { years } \\
\text { - organizational ability to } \\
\text { oversee stewardship activities } \\
\text { for } 40 \text { years }\end{array}$ \\
\hline Cost Estimates & $\begin{array}{l}\text { High stewardship cost due to } \\
\text { long time frame and } \\
\text { possibility of needing to } \\
\text { replace caps; reasonable } \\
\text { contamination reduction costs }\end{array}$ & $\begin{array}{l}\text { Medium stewardship cost due to } \\
\text { shorter time frame; } \\
\text { high cost of contamination } \\
\text { reduction and mitigation if } \\
\text { technology is unsuccessful }\end{array}$ & $\begin{array}{l}\text { Lower stewardship cost due to } \\
10 \text { years of government } \\
\text { ownership; medium to high cost } \\
\text { of developing the hot spot } \\
\text { removal technology }\end{array}$ \\
\hline
\end{tabular}


$\Delta$ 


\section{Section 5 \\ Managing the Stewardship Program}

If a decision is made to pursue a stewardship program, the tasks of implementing, monitoring, and assessing the program, as well as making any subsequent program modifications, will flow from the base stewardship plan designed and selected during the evaluation phase. In that phase, decision makers had to design an anticipated stewardship program in order to evaluate it. The task now is to implement the design and establish the systems and protocols that will be put in place to monitor, assess, and possibly modify the program.

The key elements in managing an integrated stewardship program are developing the performance objectives established for the components and the stewardship program as a whole (hereinafter, stewardship performance objectives), managing the information gathered through monitoring, conducting the periodic assessments, and modifying or terminating the program on the basis of the assessment. Figure 7 demonstrates this relationship.

\subsection{Implementing a Stewardship Program}

Implementing the stewardship program requires putting the components in place and establishing stewardship performance objectives for them. The process of implementing the components includes constructing containment systems, developing the legal documents required to effectuate land use controls, and building incentives into the organizational system to encourage effective management of the stewardship program. The actual processes and details involved in implementing the program will be highly site specific.

Performance objectives for the stewardship components describe their expected levels of functioning and become the basis for assessing component and over-all stewardship effectiveness. For example, a performance objective for land use controls could be no occurrence of unapproved land uses. A performance objective for a containment system could be to ensure that the structural integrity of the system is sound and meets the system's design specifications. A performance objective for a monitoring system for the containment system might be that weaknesses in the system's structural integrity are identified before the system fails.

Performance objectives should also be created for the overall stewardship program. An example of such an objective is the risk level that must be obtained before the site can be released for unrestricted use. 


\section{Decision Process Cycle}

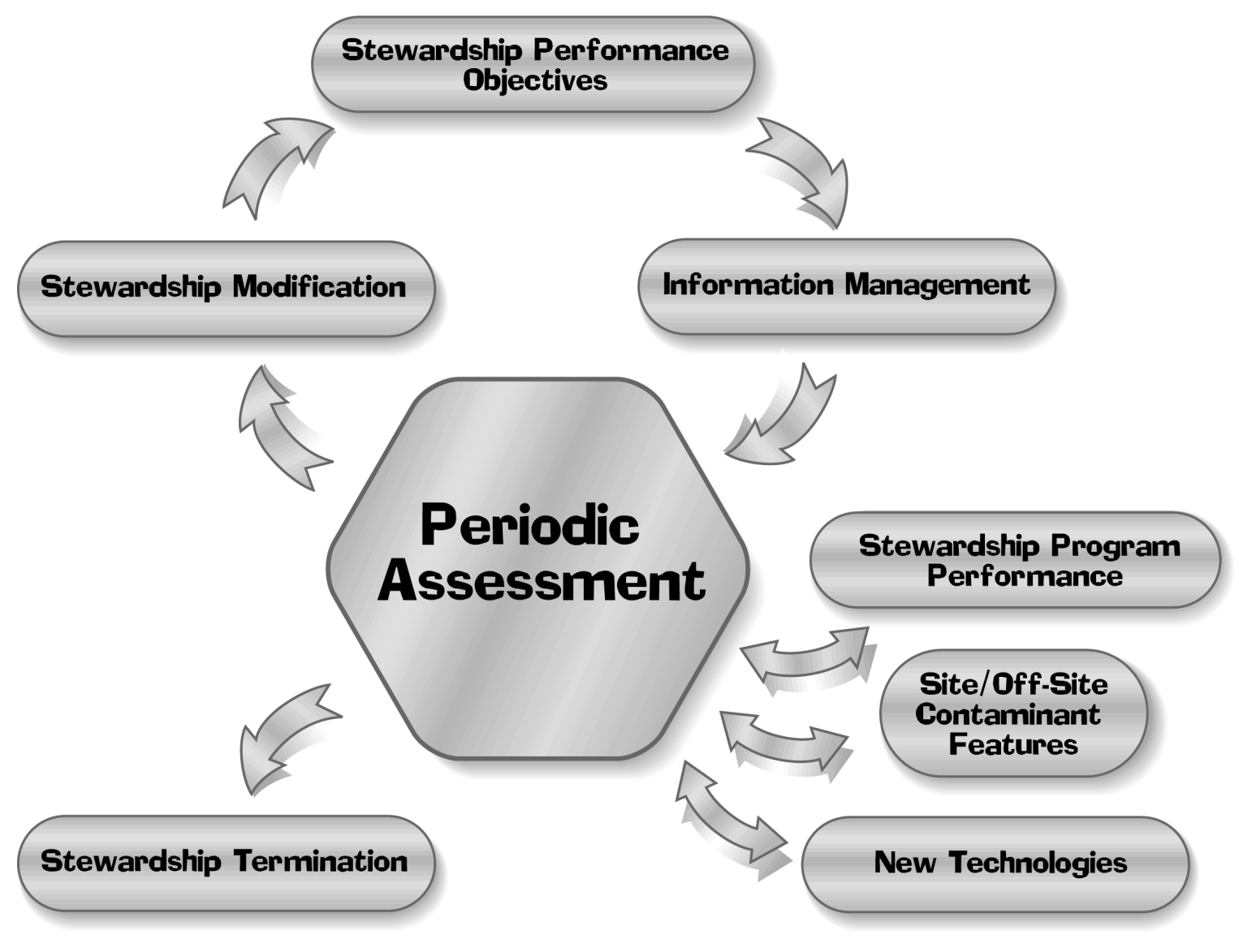

Figure 7 Decision Process Cycle

\subsection{Monitoring a Stewardship Program and Managing Information}

The performance of the stewardship components and changes in contaminants, site, and off-site characteristics will need to be monitored in order to determine the degree to which stewardship performance objectives are being achieved. The information obtained through monitoring is gathered, stored, and disseminated through the information management system. Because the information gleaned from monitoring is so important to the assessment of stewardship effectiveness, it is crucial that monitoring plans:

- Measure the events or situations addressed by the performance objective (obviously, the performance objectives themselves must be written in such a way as to be measurable); 
- Produce data streams that are small enough to not overwhelm an information management system and the organizational system that assesses monitoring data;

- Produce data streams large enough to accurately and reliably measure performance;

- Include adequate periodicity of monitoring to capture relevant events and situations;

- Contain triggers that indicate the need to modify the stewardship components;

- Contain contingency plans that describe what should happen when a trigger is activated; and

- Include periodic reassessments to determine whether more reliable and cost-effective monitoring technologies and methods are available.

The very best monitoring plans will be worthless unless the information they gather is appropriately stored, easily retrieved, and highly usable by the people who must assess stewardship performance and make decisions about its continuance, modification, or termination. The information management system must be designed to accommodate these activities cost effectively and reliably.

\subsection{Assessing the Stewardship Program}

Continual and periodic assessments of risks and costs are the two methods for assessing stewardship program performance. Continual assessment is accomplished through the triggers built into monitoring plans. When a trigger is activated, it indicates that a prompt assessment is called for to address the detected problem. Periodic assessments, by comparison, are comprehensive of the entire stewardship program, the site, the contaminants, and off-site areas and are performed on a schedule dictated by the risks posed by the site. Periodic assessments are done at the end of the stewardship time blocks represented in Figure 4 and are the subject of this section.

The periodic assessment process has two steps. The first step requires assessing the performance of the components in relation to their performance objectives and characterizing site contaminants, the site, and off-site areas. It is an evaluation of the risk and cost implications of the performance of the components in light of the characteristics of the contaminants, site, and off-site areas.

For example, if monitoring indicates that the containment system component has performed within its objectives and the contaminants have substantially decayed, the risk from a contaminant release has probably also decreased. The cost of the containment system may be reduced if less monitoring is required. Alternatively, if the containment system has appeared to deteriorate and the contaminants have not decayed, the risk level posed by the site will probably increase. The expected cost of containment will also likely increase if additional monitoring is required to detect any breach of the containment system. 
Competently completing this step requires the most reliable information available. Obviously, not all the information that is required can be known definitively (e.g., the subsurface migration of contaminants). For this reason, models take on great importance in assessing stewardship program performance. To be effective, however, models must be based on scientifically sound theory and supported with sound data. Synergism should exist in the stewardship program between the monitoring data that is gathered and the models used to predict and assess stewardship program performance and site risk. Monitoring data should be used to verify or modify models as needed.

The last assessment step is deciding if the risks and costs identified in the first step should result in terminating, continuing, or modifying the stewardship program. Figure 8 portrays the deliberation process of the last step.

In the process of deciding the future of the stewardship program, the initial determination is whether the program can be terminated. The basis for this decision

\section{Reassessing the Stewardship Program at Lakeview, Oregon}

The riprap on the cover of this UMTRA site is degrading at a faster rate than expected. As part of the site reassessment, a risk assessment will be done to determine the effect of the degraded material on exposure pathways. The risk assessment will form part of the basis for deciding if and how the stewardship program should be changed. would be that site contaminants no longer create unacceptable risks, either because they have sufficiently decayed or the regulatory standards that define what constitutes unacceptable risk have been modified. (Termination of the stewardship program is the subject of the next chapter.)

If the stewardship program cannot be terminated, decision makers should determine whether complete remediation of the site is now possible because of new remediation technologies. If complete remediation is possible, decision makers must then decide if it is reasonable. Making the reasonableness determination requires comparing the risks and costs of employing the new remediation technology against the risks and costs of continued stewardship. To fairly make this comparison, decision makers will first need to identify any scientific and technical advances in monitoring, information management, containment, organizational, and land use control systems or remediation technologies that could lead to a modified stewardship program with lower risks and costs than the existing one. To decide if complete remediation is reasonable, the risks and costs of the modified stewardship program would be compared with the risks and costs of employing a new remediation technology. 


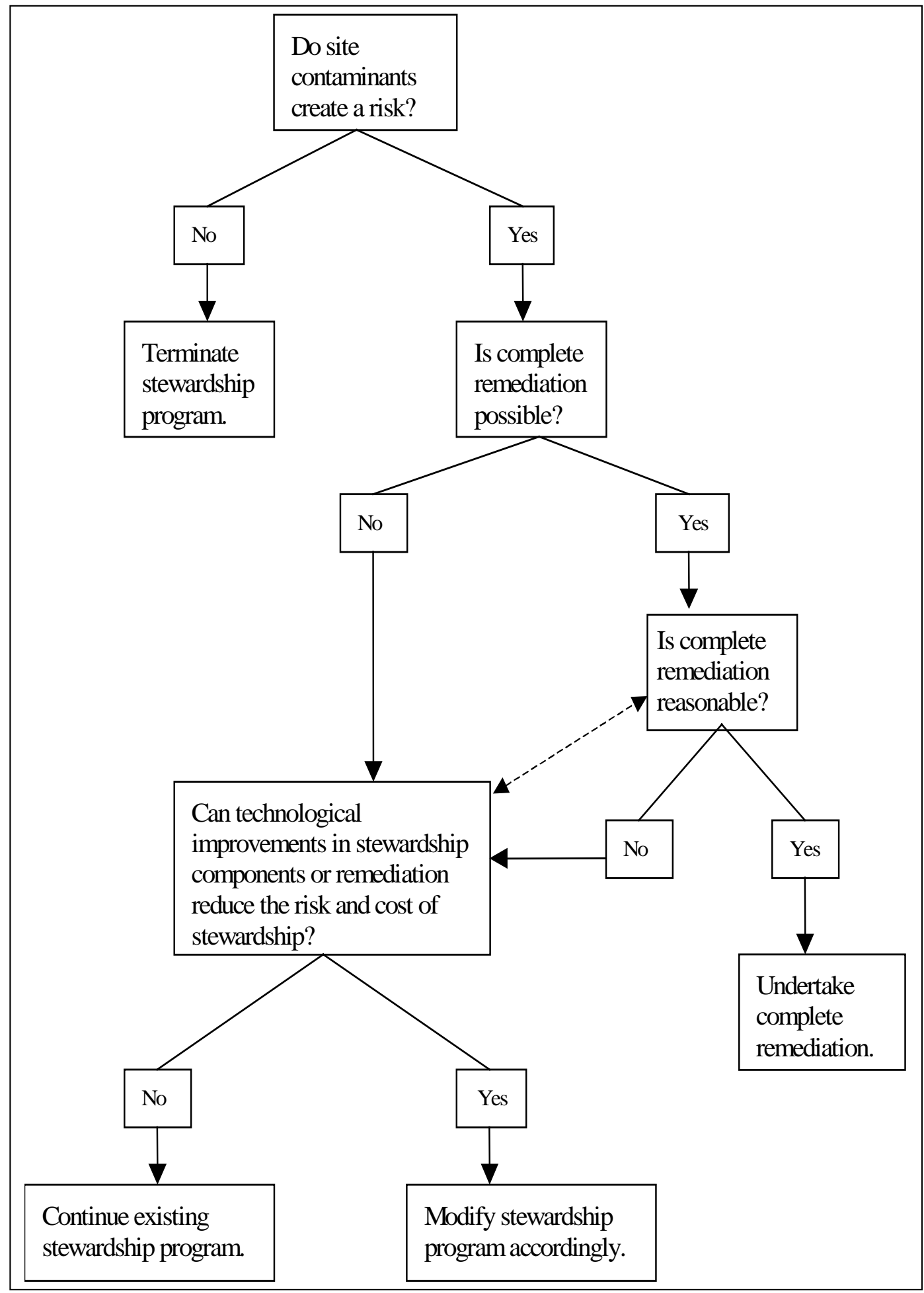

Figure 8 Assessing the Future of the Stewardship Program 
Since risk and cost considerations will drive the decisions about the future of the stewardship program, it is vitally important that the stewardship assessment process utilize:

- The best available risk and cost assessment methods,

- The applicable regulatory standards that define what constitutes acceptable risk, and

- Well-trained people who understand and can interpret and communicate the information necessary to complete the assessment.

\subsection{Modifying the Stewardship Program}

If the stewardship program cannot be terminated, the scientific and technical advancements identified in the assessment stage as mechanisms for reducing stewardship risk and cost should be built into a modified stewardship program. Stewardship performance objectives may need to be changed to reflect the modifications. A modification to one stewardship component (e.g., remote sensors replace monitoring wells) can lead to modifications of other components (e.g., the information management system must be able to handle any new monitoring reports; new technical staff might be needed in the organizational support system). The modifications to the

Modifying Stewardship in Response to a New Technology

The pump and treat system put in place by DOE when the Pinellas site in Florida was originally transferred to a private party several years ago is being upgraded to include newer technologies expected to be more effective: biosparging of organic contaminants, in situ thermal treatment of DNAPL contaminants, and pump and treat with air stripping.

stewardship program, and the information upon which they were based, must be fully documented and maintained in the information management system. 


\section{Section 6 \\ Terminating a Stewardship Program}

Terminating site stewardship requires a determination that the site no longer presents an unacceptable risk. It also requires documentation of the determination and the basis for the decision.

There are two reasons why a site would no longer pose an unacceptable risk. The first is that the contaminants no longer present a risk to human health because they have decayed to the point that they are no longer hazardous. The second reason is that the regulatory standards that define what constitutes unacceptable risk have been changed so that a formerly unacceptable risk is now considered an acceptable risk.

Regardless of the reason for making the determination that the site no longer poses an unacceptable risk, justifying the decision for regulators and interested members of the public requires accurate data on the state of the contaminants (e.g., volume and toxicity) and the site (e.g., exposure pathways). This underscores the need for thorough and consistent contaminant and site monitoring throughout the stewardship period and good information management and analysis of the monitoring data. Only good and defensible data will be useful in demonstrating that the site is within the acceptable risk range and the land can be released for unrestricted use.

The basis for the determination and the decision documents agreed to by regulators must also be fully documented and made part of the information management system for the site. The information management system component of stewardship must continue - though at a reduced scale - even though the other stewardship components will terminate. The experiences at the Chariot Site in Alaska and Site A in Illinois demonstrate the need for the information management system to survive the stewardship program.

The post-stewardship management information system would not need to retain all the information it contained before stewardship termination. When the management information system was initially established, procedures and logic were necessary to determine what information should be kept and how it should be maintained. Similarly, procedures and logic

When Information Management Systems Fail

Remediation at the Chariot Site in Alaska was considered complete, and the site was "closed." Seven years later, the site was re-evaluated for additional remediation because of stakeholder concerns about the level of cleanup that had been done. Effective information management and communication may have averted the reopening.

Recharacterizing Site A in Illinois cost several million dollars after unexpected contaminants were found. The nonavailability of characterization data used to support site closure in the 1970s contributed to that high cost. will be required to determine what post-stewardship information should be retained. 
$\Delta$ 


\section{Section 7 \\ Scientific and Technical Developments Necessary for Stewardship Programs}

The discussions in Chapter 4 on the components of a stewardship program included brief descriptions of their ideal attributes. This chapter compares those attributes with the present state of the components and identifies science and technology developments that should be pursued to address gaps between the ideal and the real attributes. The desired attributes, weaknesses, and research needs of risk assessments and cost assessments are also included because of the significant role they play in stewardship. Because of the long time frames associated with stewardship, scientific and technical research and development should be oriented toward technologies, concepts, and processes that are reliable, low cost, and subject to easy modification or replacement.

\subsection{Containment Systems}

The ideal containment system would function effectively for as long as the contaminants it holds present a risk, its integrity and performance would be capable of being monitored, and its maintenance costs would be low. To date, experience with most containment systems is generally too meager to draw conclusions about how they measure up to these ideal attributes.

Disposal cells, caps, and barriers have been in use for 20 to 30 years. Although some information can be gathered from their performance to date, it is probably too soon to project if they will provide assured confinement for the length of time they need to be in effect. In the case of tanks used to contain radioactive wastes at DOE's Hanford and Oak Ridge sites, experience over a 60 -year period indicates that they do not provide adequate containment and can be difficult to monitor and remediate. Projecting the ability of natural containment systems to meet the desired attributes is complicated by the fact that related monitoring data may be limited to only a few decades.

Research to address the uncertainties surrounding the performance of containment systems could center on these topics:

- Designs that take into account their eventual replacement;

- Designs that take into account retrieval of container contents for possible treatment or reuse in the future;

- Systems that have built-in sensors to monitor structural integrity and detect flaws before contaminant releases occur;

- Characteristics of existing containment systems that appear to be operating successfully; 
- Models for determining long-term system performance;

- Transferability of the designs that meet DOE performance objectives for low-level radioactive waste disposal to other containment systems;

- Transferability of the DOE performance assessment processes (used by DOE to determine whether low-level radioactive waste disposal sites will be protective of human health for 1,000 years) to determine long-term performance of other containment systems; and

- Extent to which disposal cell size is a factor for success or failure.

\subsection{Land Use Controls}

The required attributes for land use controls are that they be capable of enduring for the length of time they must be in effect. In addition, they must be capable of being implemented, monitored, and enforced. Land use controls, for purposes of this discussion, will be divided into two categories on the basis of whether the federal government retains or transfers land that must be access or use controlled.

When the federal government transfers land (i.e., ownership is no longer held by the federal government), easements, permit programs, zoning, and deed notifications could be used as land use controls. The authority for these controls originates in real estate practices that are embodied in laws or court rulings. These land use controls are commonly used and are generally reliable, but their effectiveness in stewardship programs is questionable for several reasons.

Some of these land use controls may not be capable of being implemented. A federal agency might transfer land to a private party with the understanding that the land would be restricted to commercial use and the expectation that the local government will zone the land accordingly. The zoning restriction would be the land use control. Zoning authority is granted to local governments through the state. If the local government did not have adequate authority to impose zoning, the land use control could not be legally implemented.

Even if land use controls can be implemented, they may not endure for the length of time they will need to be relied upon to limit land use or access. Through time, zoning boards will change in composition, authority, and values. Although boards may still be aware of the basis for the zoning, they can be subject to pressure from land developers and citizens interested in increasing the local tax base to grant zoning variances or change zoning classifications. It is also reasonable to believe that zoning boards will, through time, lose their awareness of why certain areas should be zoned for certain uses only.

Fallibility of memory and record keeping systems is not limited to zoning boards. Systems for recording easements and deed notifications can break down, and all records 
of these land use controls could be lost. State or local agencies responsible for determining whether permits can be granted for certain land uses (e.g., construction, well digging, or excavation below a certain level) can forget that permits are not to be granted for certain areas because of residual contamination.

If the recording system for easements does not break down, those easements may still not endure. Some states may have restrictions on the number of years land use restrictions can be in place. In some cases, an easement may extinguish when land is resold.

Land use controls can also fail because they may not be enforceable. Some easements can be enforced only by the easement holder. If the terms of the easement are violated, but its holder does not enforce it, the easement can be extinguished and the land use control can be lost.

The land use control may not even have an enforcement mechanism available to anyone. Deed notifications are sometimes cited as possible land use controls, and they are required by CERCLA and RCRA in some cases. However, they simply notify buyers that the land once held hazardous substances, and they contain no method for addressing harm that may arise from ignoring the notification.

Another reason that land use controls may not be effective throughout the course of the stewardship program is the diligence and cost associated with monitoring them. Diligence can decrease as the responsible organization changes its mission or places less emphasis on monitoring. This lessened attention to monitoring could be caused by the high cost of determining if easements have not been violated, zoning variances have not been granted, or permits have been granted in error.

The diligence and cost associated with land use controls imposed when the federal government retains the land can also impede the monitoring that is necessary to ensure their effectiveness. When the federal government retains land, the land use controls that could be utilized are fences, guards, signs, and leases; the authority for these land use controls derives from the government's right to restrict use of its property. The time and cost invested in ensuring that signs are still present and legible, fences are still standing and have not been breached, and lease conditions have been adhered to can be extensive, and these enforcement activities could be prime candidates for cut backs when budgets become tight.

These potential weaknesses of land use controls could be addressed through research into these areas:

- New forms of easements, such as environmental restoration easements, that have greater survivability and enforceability;

- Risk assessment methods that take into account land use control failure scenarios and their impact on stewardship effectiveness; 
- Remote sensing systems to lower monitoring costs;

- Interactive information management systems that indicate when a deed transfers to a new owner, which then triggers an investigation to determine if the easement has transferred; and

- Accessible and economical geographic visualization systems for use by zoning boards, as well as permit program and deed registry administrators, to aid them in remembering areas with land use restrictions.

\subsection{Monitoring Systems}

Well-designed monitoring systems reliably, validly, and cost-effectively measure the performance of stewardship components, contaminant activity, and relevant site and offsite characteristics. They must be designed to be functional for the life expectancy of the stewardship program. These systems must also be monitored to ensure that they are operating effectively or incorporate the best approach to performance measurements.

Monitoring plans must take into account the uncertainties associated with the stewardship components, the site, the contaminants, and off-site characteristics. Plans will contain triggers that prefigure an event that needs to be addressed. The plans will also include contingency plans that describe what should happen when a trigger is activated. Monitoring plans should also be designed so that data collected are usable for refining models, communicating contaminant status, and assessing the performance of the stewardship program.

The initial available indicators of the present state of affairs of stewardship monitoring programs point to their high cost. The type of monitoring envisioned for the stewardship program - monitoring the performance of stewardship components as well as the characteristics of contaminants, the site, and off-site areas - is already under way for 30 DOE sites through the Grand Junction Project Office. Although these sites are generally small and not complexly contaminated, their monitoring costs in FY 2000 were expected to be $\$ 2.9$ million. By FY 2006, the anticipated cost for monitoring 61 sites is projected at \$13.5 million (DOE 2000a). The DOE Inspector General estimated that in FY 2000, DOE would spend $\$ 57$ million on groundwater monitoring alone at 31 of its sites (DOE 2000b).

In addition to the potentially high costs associated with stewardship monitoring systems, they can be prone to several weaknesses. Monitoring systems could focus only on monitoring the contaminant and the containment system, which could result in inadequacies or failures of the other stewardship components or relevant changes in the site and off-site areas that are not detected. It is possible for decision makers to simply continue the monitoring program and never reassess it to determine if conditions indicate the need for modifications in monitoring periodicity or methodology. For example, a site might continue to monitor the full analytical suite of site contaminants, when monitoring 
for a few fingerprint compounds might be just as effective but much less resource intensive.

Another possible weakness in the monitoring system is that it might not be designed to be compatible with the information management system. This situation could result in lost information or inefficient, and therefore costly, maintenance and communication of the monitoring data.

These weaknesses in monitoring systems point to the need for research in the following areas to achieve more cost effective monitoring technologies and methodologies:

- Methodologies to select baseline monitoring points and compliance monitoring points;

- Technologies capable of detecting fingerprint compounds that represent contaminants of concern;

- Technologies that can directly read the fingerprint compounds and automatically upload the results to the management information system;

- Technologies that are capable of assessing ecological "health" through direct or near direct readings of ecological health indicators (e.g., a physical or chemical water quality parameter could be an indicator of the health of an ecological system);

- Technologies or methodologies to measure containment system integrity;

- Remote sensing technologies to detect changes in site and off-site conditions;

- Real time sensors; and

- Methodologies for determining monitoring frequency on the basis of changes in contaminants, the site, off-site areas, containment systems, and land use control vulnerabilities.

\subsection{Information Management Systems}

The ideal information management system would be streamlined and cost efficient, with well-developed procedures and logic for identifying and capturing the legacy and ongoing monitoring information relevant to the stewardship program. The system would be able to manage, preserve, and disseminate information in a wide variety of formats that meet the differing needs of a wide variety of users (e.g., regulators, modelers, risk and cost assessors, members of the public, and subsequent organizations with responsibility for the stewardship program). Simply put, the information maintained by the system would be relevant, reasonably priced, and useful. 
Information management systems used for existing stewardship activities would likely consist of the administrative record maintained by the site before it went into a stewardship mode. The record, however, may not include all the information that is relevant for stewardship purposes. The administrative record would probably include formal remediation reports, but, because of the large volumes of data, they may only summarize the raw data generated during site characterization and remediation. These summaries may not be helpful in conducting stewardship program assessments.

Another reason why valuable data may be lost is that sites may have had conflicting purposes for their pre-stewardship information management system. One purpose may have been data preservation, with a secondary purpose being to support technical work ongoing at a site. Because preservation emphasizes security, control of information, and limited access, the system might not have been very "user-friendly." This could lead to the development of parallel databases that served specific project needs. These parallel databases may well contain information that, for whatever reason, is never captured for the formal data archiving system.

Gathering and maintaining relevant information can be quite costly. If the cost of the system is too high, it could lead decision makers to make unfortunate and unwise reductions in the information that is gathered and maintained.

Even if information is relevant and inexpensively maintained, it is meaningless if it cannot be retrieved and conveyed in useful ways. Problems with retrieval relate to where and how information is stored and its ownership. Documents for the Formerly Utilized Sites Remedial Action Program (FUSRAP) and Uranium Mill Tailings Remedial Action (UMTRA) sites, for which DOE is the administrative record custodian, are stored in a microfiche format in central repositories (Grand Junction, Colorado, for UMTRA sites and Oak Ridge, Tennessee, for the FUSRAP sites). Access to these documents is open to the general public, but gaining access requires a person to physically come to the offices and be comfortable with searching through and using microfiche.

Another retrieval difficulty with the way information is stored relates to the rapidly changing technology base associated with information systems in general. For example, valuable information may be stored in forms that were state of the art at the time, but quickly became outmoded, obsolete, and inaccessible. Examples of information storage technologies that have either disappeared or are disappearing include computer tapes originally used for preserving large data files, 5.25-inch floppy disks, and microfiche. Valuable stewardship information may be lost if information is not migrated from existing to newly emerging technologies.

If the management information system and the information it contains are proprietary to the organization with present stewardship responsibilities, they may not be usable to subsequent organizations. In this case, either extensive amounts of stewardship monitoring data could be lost when new organizations take over, or the stewardship program would always be in thrall to the same organization. 
These possible weaknesses in management information systems should be addressed through research in the following areas:

- Approaches (e.g., web-based systems, hard-copy maps, and combinations of paper and electronic information delivery systems) that make data accessible in a variety of user-appropriate formats;

- Robust systems for which the danger of obsolescence is low;

- Method by which people most efficiently process information and how that translates into information delivery systems;

- Protocols and procedures for ensuring the quality and persistence of data;

- Systems that are automated to the maximum extent possible;

- Methods to ensure that information systems are not proprietary to any one organization;

- Systems that are robust but adaptable to programmatic or organizational change; and

- Procedures for determining the legacy and monitoring information to be incorporated into information management systems.

\subsection{Organizational Systems}

The ideal characteristics of the organization responsible for managing the stewardship program are that it has (1) the authority, responsibility, funding, and incentives to carry out its obligations; (2) the appropriate skill mix of personnel; and (3) the policies and processes that promote stewardship program management. With these attributes, an organization may be in a good position to survive for the length of time it must function to manage the stewardship program.

Unfortunately, our experience with organizations that support activities that have endured for decades and even hundreds of years with their mission intact is quite limited. Examples that are often proposed as analogs for stewardship because they have endured are cemeteries, parks, museums, and religious institutions. These examples are questionable analogs because a substantial reason for their endurance is strong public support. They survive because of the aesthetic, cultural, or spiritual value the public attributes to them. The public would not ascribe these same values to contaminated land that must be use restricted.

Although we can identify the attributes that organizations need in order to endure and manage a stewardship program, we are less sure of the type of organization that would be most effective, or the structure it should have. Nor are we sure of the incentives that would motivate the organization to continue its mission, or the specific funding 
mechanisms or policies and procedures that would most reliably ensure organizational stability. Research to address these unknowns about organizational systems would include the following considerations:

- What organizational type is best suited to the task of stewardship?

- private

- governmental (federal, state, local, or combinations thereof)

- quasi-governmental

- What organizational structure is most appropriate?

- How will the organization be legitimized to have the authority to carry out its mission?

- What incentives will be built into the organization to ensure it stays "on mission?"

- What funding mechanisms are needed to ensure the durability and maximum operation of the organization?

- How shall the organization be held accountable for its actions or non-actions? And

- What is the proper mix of personnel needed to manage the stewardship program?

\subsection{Risk Assessments}

The ideal risk assessments for stewardship would be based on comprehensive and accurate data and models that take all conditions into account and are future oriented. The process and assumptions would be understandable to all interested parties, thus creating greater public confidence in the risk assessment results.

The present state of risk assessment methodologies falls somewhat short of these attributes. The data and models available to risk assessors may be incomplete or incorrect. Risk assessments tend to be used to assess relatively near-term risks with a focus only on human health risks, although ecological risk assessment methodologies are emerging. Assessments of risk tend to evaluate different exposure routes and pathways separately rather than comprehensively. Many of the toxicity levels used to determine risk are based on extrapolations from animal toxicity data and may be inappropriately high or low. The public is often skeptical about risk assessment results because they do not fully understand the process and its uncertainties and assumptions.

The research needs for risk assessment resulting from these observations are as follows:

- Risk assessment processes, assumptions, and results that are transparent and accessible to the interested public; 
- Enhanced ecological risk assessment methodologies;

- Better information on the actual toxic effects of contaminants on people;

- Cumulative risk assessment methods;

- New modeling techniques that address the uncertainties associated with longer time frames;

- Failure modes for containment systems, land use controls, monitoring systems, and organizational systems;

- Toxicity studies to ensure that risk levels are based on toxicity rather than detection limits;

- Methods and models that project demographic, climate, hydrology, and hydrogeologic changes and incorporate them into the risk assessment; and

- Toxicity studies to ensure that regulatory standards that define what constitutes risk are neither too lax nor too stringent.

\subsection{Cost Assessments}

Assessments used to determine the costs of stewardship and complete remediation in order to weigh their merits should utilize life-cycle costing methods that are based on good data and assumptions so as to provide realistic results. The maximum amount of agreement should be sought among interested parties as to how phenomena that are normally not described in quantitative terms (e.g., the value of human life, ecosystem health, cultural resources, individual plant or animal species) will be factored into the cost assessment. Efficiency and equity should also be equally considered in cost assessments.

As with risk assessments, potential weaknesses in current cost assessments are the absence of accurate data and comprehensive models and methodologies. A component of the comprehensive nature of cost assessments is the geographic and temporal boundary placed on the assessment. If the period of years covered by the cost assessment is too long or too short, the assessment can be inappropriately skewed. The same result could occur if the analysis of the cost impacts of stewardship and complete remediation is limited only to the site under review and the impacts to the surrounding land are ignored. Cost assessment results might also be met with skepticism if they are based on valuations of normally nonquantifiable phenomena that are seen as inappropriate. 
Research into the following topics could improve the cost assessments that are such an important feature of stewardship:

- Accurate and comprehensive cost data on the components of a stewardship program at a site;

- Accurate and comprehensive information on the costs of complete remediation at a site;

- Good data on the costs associated with failure of stewardship components;

- Good data on the costs associated with the inability to achieve the anticipated complete remediation;

- Assessment methods that include opportunity costs that are lost (e.g., nonavailability of the site or surrounding areas for certain uses because of contamination or stigma);

- Assessment methods that include opportunity costs that are gained (e.g., the site with land use restrictions, and possibly its surrounding areas, may increase in value as natural areas since they have not been overrun with development); and

- Public involvement and communication techniques for reaching some degree of consensus on how to factor normally nonquantifiable phenomenon into cost assessments. 


\section{Section 8}

References

Brookhaven National Laboratory, 2000, Brookhaven National Laboratory Operable

Unit III Record of Decision, Environmental Restoration Division, Upton, N.Y., April 14.

National Research Council, 1999, Groundwater and Soil Cleanup: Improving

Management of Persistent Contaminants, Committee on Technologies for Cleanup of Subsurface Contaminants in the DOE Weapons Complex, Washington, D.C.

U.S. Department of Energy, 1998, Using Remedy Monitoring Plans to Ensure Remedy Effectiveness and Appropriate Modifications, DOE/EH-413, 9720, Washington, D.C., Feb.

U.S. Department of Energy, 1999, Cleanup to Stewardship, DOE/EM-0466, Washington, D.C., Oct.

U.S. Department of Energy, 2000a, Long-Term Surveillance and Maintenance Program 1999 Report, GJO-2000-130-TAR, Grand Junction Project Office, Grand Junction, Colo., March.

U.S. Department of Energy, 2000b, Groundwater Monitoring Activities at Department of Energy Facilities, DOE/IG-0461, Inspector General, Washington, D.C., Feb.

U.S. Environmental Protection Agency, 2000, Institutional Controls and Transfer of Property under CERCLA Section 120(h)(3)(A), (B), or (C), Washington, D.C., Jan. 
$\Delta$ 